\title{
A new method to determine the mixing state of light absorbing carbonaceous using the measured aerosol optical properties and number size distributions
}

\author{
N. Ma ${ }^{1}$, C. S. Zhao ${ }^{1}$, T. Müller ${ }^{2}$, Y. F. Cheng ${ }^{3}$, P. F. Liu ${ }^{1}$, Z. Z. Deng ${ }^{4}$, W. Y. Xu ${ }^{1}$, L. Ran ${ }^{1}$, B. Nekat ${ }^{2}$, \\ D. van Pinxteren ${ }^{2}$, T. Gnauk ${ }^{2}$, K. Müller ${ }^{2}$, H. Herrmann ${ }^{2}$, P. Yan ${ }^{5}$, X. J. Zhou ${ }^{1,5}$, and A. Wiedensohler ${ }^{2}$ \\ ${ }^{1}$ Department of Atmospheric and Oceanic Sciences, School of Physics, Peking University, Beijing, China \\ ${ }^{2}$ Leibniz Institute for Tropospheric research, Leipzig, Germany \\ ${ }^{3}$ College of Environmental Sciences and Engineering, Peking University, Beijing, China \\ ${ }^{4}$ Key Laboratory of Middle Atmosphere and Global Environment Observation, Institute of Atmospheric Physics, Chinese \\ Academy of Sciences, Beijing, China \\ ${ }^{5}$ Chinese Academy of Meteorological Sciences of CMA, Beijing, China
}

Correspondence to: C. S. Zhao (zcs@ @ku.edu.cn)

Received: 13 July 2011 - Published in Atmos. Chem. Phys. Discuss.: 7 October 2011

Revised: 12 January 2012 - Accepted: 22 January 2012 - Published: 2 March 2012

\begin{abstract}
In this paper, the mixing state of light absorbing carbonaceous (LAC) was investigated with a two-parameter aerosol optical model and in situ aerosol measurements at a regional site in the North China Plain (NCP). A closure study between the hemispheric backscattering fraction (HBF) measured by an integrating nephelometer and that calculated with a modified Mie model was conducted. A new method was proposed to retrieve the ratio of the externally mixed LAC mass to the total mass of LAC ( $\left.r_{\text {ext-LAC }}\right)$ based on the assumption that the ambient aerosol particles were externally mixed and consisted of a pure LAC material and a core-shell morphology in which the core is LAC and the shell is a less absorbing material. A Monte Carlo simulation was applied to estimate the overall influences of input parameters of the algorithm to the retrieved $r_{\text {ext-LAC. }}$. The diurnal variation of

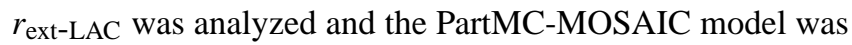
used to simulate the variation of the aerosol mixing state. Results show that, for internally mixed particles, the assumption of core-shell mixture is more appropriate than that of homogenous mixture which has been widely used in aerosol optical calculations. A significant diurnal pattern of the retrieved $r_{\text {ext-LAC }}$ was found, with high values during the daytime and low values at night. The consistency between the retrieved $r_{\text {ext-LAC }}$ and the model results indicates that the diurnal variation of LAC mixing state is mainly caused by the diurnal evolution of the mixing layer.
\end{abstract}

\section{Introduction}

Atmospheric aerosols influence the Earth's radiative balance directly by scattering and absorbing solar radiation, and indirectly by changing the albedo, cloud amount, lifetime of clouds, and precipitations (Twomey, 1974; Albrecht, 1989; Charlson et al, 1992; Rosenfeld, 1999, 2000; Zhao et al., 2006). The largest uncertainty in estimating the radiative forcing results from aerosols (IPCC, 2007). Light absorbing carbonaceous (LAC), as one of the most important components of aerosols, is considered as the dominant absorber of visible solar radiation in the atmosphere (Ramanathan and Carmichael, 2008), and hence has a positive radiative forcing on the climate system (Jacobson, 2001). Due to the lack of horizontal and vertical distributions of LAC, insufficient emission inventory and the rather limited knowledge on the mixing state of LAC, the quantity of positive radiative forcing caused by LAC is yet uncertain.

The LAC has been assigned various names in the literature, such as "black carbon (BC)", "elemental carbon (EC)", and "soot". "BC" is mostly used to emphasize its light-absorbing property. However, following Bond and Bergstrom (2006), "LAC" is used in the current study.

LAC is emitted into the ambient atmosphere by fossil fuel (diesel and coal) combustion, open biomass burning (associated with deforestation and crop residue burning), and 
cooking with biofuels (Ramanathan and Carmichael, 2008). The freshly emitted LAC often stays unmixed, while there are many processes that cause LAC to mix with other chemical components, such as coagulation with other particles, condensation of vapors onto the surface forming a coating layer, reactions with gases, and cloud processes. The mixing state of LAC is quite complicated and the optical properties of LAC are very sensitive to the mixing state (Khalizov et al., 2009). It is suggested that different mixing states of LAC affect its global direct radiative forcing by a factor of $2.9\left(+0.27 \mathrm{Wm}^{-2}\right.$ for an external mixture, $+0.54 \mathrm{Wm}^{-2}$ for a core-shell mixture with LAC core, and $+0.78 \mathrm{Wm}^{-2}$ for homogeneously internal mixture) (Jacobson, 2000, 2001).

Winkler (1973) suggested a definition of external and internal mixture of aerosols. For an external mixture, different compounds are separated as different particles, while in an internal mixture, all particles consist of the same mixture of compounds. The external and internal mixtures are two limiting cases with all intermediate states between them to be possible. Three conceptual models are usually used to describe the mixing state of LAC and other aerosol components: external mixture, homogeneously internal mixture, and core-shell internal mixture (a LAC core surrounded by a well-mixed less absorbing shell) (Seinfeld and Pandis, 1998; Jacobson, 2001). Most of the models for estimating the direct aerosol radiative forcing, as well as aerosol optical closure studies (Wex et al., 2002b; Mallet et al., 2004; Cheng et al., 2006; Ma et al., 2011) are based on the assumption of external mixture or homogeneously internal mixture for LAC and less absorbing components. However, many studies have suggested that internally mixed LAC is usually coated with a shell of less absorbing component to form a core-shell structure rather than "well mixed". Images obtained from TEM supported that LAC particles could become coated once emitted (Katrinak et al., 1992, 1993; Martins et al., 1998). Volatility tandem DMA (differential mobility analyzer) measurements showed that the majority of particles are comprised of a non-volatile core and a volatile outer layer during heavily polluted days (Wehner et al., 2009). Many studies also suggested that the use of a single particle optical model assuming an absorbing spherical core surrounded by a mantle of non-absorbing material is appropriate in the estimation of the aerosol direct radiative forcing (Jacobson et al., 2000, 2001; Chandra et al., 2004; Bond and Sun, 2005).

Many efforts have been undertaken to investigate how LAC is mixed with other aerosol components. In general, the mixing state of LAC can be obtained through two kinds of methods: direct measurements and inferences via optical closure studies.

A transmission electron microscopy (TEM) can be used for single particle analysis. The mixing state of soot particles was observed by Katrinak et al. $(1992,1993)$ and Clarke et al. (2004) with the TEM. A Single-particle soot photometer can be used to distinguish the coated soot particles (Schwarz et al., 2008) by measuring the incandescence and scatter- ing at infrared wavelengths of single particles. Moffet et al. $(2008,2009)$ used an aerosol time-of-flight mass spectrometer to yield the mixing state of soot in real-time, and a diurnal variation was found. In recent years, Tandem DMAbased techniques were widely applied in aerosol measurements. A high humidity tandem DMA (Hennig et al., 2005) can provide size-resolved fractions of externally mixed hydrophobic particles (Liu et al., 2011), while a volatility tandem DMA can be used to yield size-resolved fractions of particles with different volatility that usually indicate different mixing states of LAC (Wehner et al., 2009; Cheng et al., 2009).

Besides the direct measurements, some studies inferred the LAC mixing state via optical closure studies. Most of them were based on the Mie model and the dependence of mass absorption efficiency of LAC on its mixing state. Mallet et al. (2004) calculated the single scattering albedo $(\omega)$ from in situ aerosol data with the assumption of external and homogeneously internal mixture for LAC and other components, and compared the two calculated $\omega$ with the values of Aerosol Robotic Network (AERONET) sun-photometer measurements. They found that LAC was externally mixed in the urban area. Dey et al. (2008) did a similar optical closure study in India to infer the mixing states and made an improvement by assuming six cases of aerosol mixing state in the calculation. They found that the probable aerosol mixing state had seasonal variations. Based on in situ aerosol microphysical and chemical measurements and a two-parameter aerosol optical model, Cheng et al. (2006) developed an internally consistent algorithm to yield the ratio of externally mixed LAC to the total mass of LAC. The aerosol absorption coefficients were calculated using aerosol particle number size distributions (PNSDs) and size-resolved chemical information with a variable mass ratio of externally mixed LAC. The best estimation of the mass ratios was derived from minimizing the difference between the calculated absorption coefficients and the values measured by MAAP (multi-angle absorption photometer, Petzold et al., 2002). However, due to the low temporal resolution of the aerosol chemical composition data, only two ratio values could be retrieved for each day.

With the rapid growth of population and economy in China, emissions of anthropogenic pollutants have increased dramatically in the past several decades. The widespread consumption of coal and biomass fuels makes China a significant source region of LAC. It has been reported that the LAC amount emitted in China make up about one fourth of globally emitted anthropogenic LAC (Cooke et al., 1999; Street et al., 2001; Bond et al., 2004). Megacities in China suffer severe air pollution (Ran et al., 2009; Liu et al., 2009), meanwhile influencing the neighboring regions. One of the most polluted areas in the world is the North China Plain (NCP) region (van Donkelaar et al., 2010), where two of the most densely populated megacities in China, Beijing and Tianjin, are located (Xu et al., 2011). In such highly polluted areas 
with high aerosol loading and concentrations of gases pollutants, aerosol aging processes may be quite different from what has been previously recognized, thus the mixing state of LAC might be much more complicated. However, studies addressing the mixing state of LAC in this region are currently very limited (Cheng et al, 2006; Wehner et al., 2009).

In this paper, an optical closure study was performed using in situ aerosol data measured at a regional site in the NCP. The hemispheric backscattering fractions (HBFs) calculated with three assumed LAC mixing states were compared with the measured values. A new algorithm was applied to infer the mass ratio of externally mixed LAC to the total mass of LAC ( $\left.r_{\text {ext-LAC }}\right)$, assuming the mixing state of LAC as partially externally mixed and partially core-shell mixed.

In Sect. 2, the site and instruments of the campaign are introduced. The new method for inferring the $r_{\text {ext-LAC }}$ is described in Sect. 3. Sect. 4 presents the retrieved $r_{\text {ext-LAC, }}$ a three-day case study, as well as the uncertainty study. The summary and conclusions are presented in Sect. 5.

\section{Measurements}

\subsection{The field site}

The HaChi (Haze in China) campaign took place in summer 2009 (12 July to 14 August, 193-226 DOY) in Wuqing, a suburban site in the Northern NCP and well representative of regional anthropogenic aerosols. The Wuqing town is situated between two megacities: Beijing (16 million inhabitants, $80 \mathrm{~km}$ away in the NW of Wuqing) and Tianjin (10 million inhabitants, $30 \mathrm{~km}$ away in the SSW of Wuqing) with about 0.8 million inhabitants. The map of the site and the area around can be found in Xu et al. (2011). During the campaign, particle number size distributions, aerosol light scattering coefficients, as well as LAC mass concentrations were continuously measured.

The measurements were conducted in a container, in which the temperature was maintained at $22^{\circ} \mathrm{C}$. Air samples were collected with a $\mathrm{PM}_{10}$ inlet $\left(16.671 \mathrm{~min}^{-1}\right)$ installed on the top of a stainless steel tube with a diameter of $3 / 4$ inch $(19 \mathrm{~mm})$ and $7 \mathrm{~m}$ a.g.l. The samples were split into several flows inside the container, passing through stainless steel tubing, to different instruments. The residence time for samples in the inlet system was about $5 \mathrm{~s}$. An automatic aerosol diffusion dryer (Tuch et al., 2009) was installed upstream all of the instruments to keep the relative humidity $(\mathrm{RH})$ of the measured sample below $30 \%$.

\subsection{Instrumentation}

A Twin Differential Mobility Particle Sizer (TDMPS, IfT, Leipzig, Germany) (Birmili et al., 1999) and an Aerodynamic Particle Sizer (APS Model 3320, TSI, Inc., Shoreview, MN USA) were employed to measure PNSDs. Both were operated at $\mathrm{RH}<30 \%$. The raw TDMPS and APS data were inverted and merged to yield the PNSDs with the range of equivalent diameter from $3 \mathrm{~nm}$ to $10 \mu \mathrm{m}$. Details can be found in Ma et al. (2011). The temporal resolution of the PNSD data was $10 \mathrm{~min}$.

The scattering coefficients $\left(\sigma_{\mathrm{sp}}\right)$ and hemispheric backscattering coefficients $\left(\sigma_{\mathrm{bsp}}\right)$ for dry aerosols were measured by a total scatter/back scatter, integrating nephelometer at the wavelengths of 450, 550 and $700 \mathrm{~nm}$ (TSI, Inc., Shoreview, MN USA, Model 3563) (Anderson et al., 1996, 1998), with a temporal resolution of $1 \mathrm{~min}$. The nephelometer was calibrated beforehand using $\mathrm{CO}_{2}$ (Anderson et al., 1996). Particle free air checks were performed once a day.

A multi-angle absorption photometer (MAAP Model 5012, Thermo, Inc., Waltham, MA USA) was employed to measure the absorption coefficients $\left(\sigma_{\mathrm{ap}}\right)$ for dry particles with a sampling frequency of $1 \mathrm{~min}$. The instrument determines $\sigma_{\text {ap }}$ via simultaneous measurements of light $(637 \mathrm{~nm})$ passing through its filter and scattered back from particles accumulated on its surface. It operates at two detection angles to resolve the influence of light-scattering aerosol components on the angular distribution of the back-scattered radiation (Petzold and Schönlinner, 2004). The MAAP determines absorption coefficients directly and converts them to LAC mass concentrations with an assumed mass absorption efficiency (MAE) of $6.6 \mathrm{~m}^{2} \mathrm{~g}^{-1}$. This constant has been validated by the comparison between the impactor-derived elemental carbon mass and the MAAP measurements, which will be discussed in Sect. 4.4.2.

\section{Methodology}

\subsection{Two-parameter aerosol model}

A simplified aerosol model (Wex et al., 2002b; Cheng et al., 2006) was applied to aerosol optical calculations in this work. In the model, aerosol components are divided into two classes in terms of their optical properties: the lightabsorbing component (i.e. LAC) and less absorbing components (comprising inorganic salts and acids such as sulfates, nitrates, ammoniums, as well as most of the organic compounds). Although the chemical properties of numerous less absorbing compounds might be different, their refractive indices are basically the same, implying that the aerosol optical properties are not sensitive to their ratios. Therefore, the aerosol optical properties can be well represented with the two-parameter assumption in the Mie calculation (Wex, 
2002a). This aerosol model is also widely used in aerosol direct radiative forcing estimations (Myhre et al., 1998; Kristjansson, 2002), but usually only LAC and sulfates were included.

The refractive indices of LAC and less absorbing components in the aerosol model were selected from related literatures (Ouimette and Flagan, 1982; Hasan and Dzubay, 1983; Sloane, 1984; Seinfeld and Pandis, 1998; Covert et al., 1990; Tang and Munkelwitz, 1994). The real part of the refractive index for LAC was chosen to be 1.80, and the imaginary part was set to be $0.54 \mathrm{i}$, which was the average value for the wavelengths of 450, 550 and $700 \mathrm{~nm}$ (d' Almeida et al., 1991). The refractive index of the less absorbing components was set to be $1.55-1 \mathrm{e}-7 \mathrm{i}$.

For the mixing state of LAC, new evidences supporting the core-shell structure of LAC aerosols have been found in the simulation of nephelometer measurements. The nephelometer-measured HBF was simulated based on three assumed mixing states of LAC: external mixture, homogeneously internal mixture, and core-shell mixture. The HBF calculated with the assumption of core-shell mixture gives the highest results, which are about $30 \%$ higher than those calculated with the assumption of external mixture. While the HBF calculated with the assumption of homogeneously internal mixture are the lowest, about $10 \%$ lower than those calculated with the assumption of external mixture. The HBF given by nephelometer are always between the values calculated with the assumptions of external mixture and coreshell mixture. It definitely suggests that the sampled aerosols might be partially externally mixed and partially core-shell mixed rather than externally mixed and homogeneously internally mixed. More details will be discussed in Sect. 4.1.

Consequently, aerosols are divided into two kinds in this study: the completely externally mixed LAC and a LAC core surrounded by a less absorbing component shell. To quantify the mixing state of LAC, $r_{\text {ext-LAC }}$ is defined as the mass fraction of externally mixed LAC $\left(M_{\text {ext-LAC }}\right)$ in total LAC $\left(M_{\text {LAC }}\right)$ :

$r_{\text {ext-LAC }}=\frac{M_{\text {ext-LAC }}}{M_{\text {LAC }}}$

If all LAC is externally mixed and there is no core inside the less absorbing component, $r_{\text {ext-LAC }}$ is 1 ; while $r_{\text {ext-LAC }}$ is 0 if all LAC is covered by less absorbing component. For

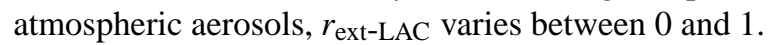

\subsection{Mie code}

To simulate the measurements of TSI 3563 nephelometer, a modified BHMIE code and a modified BHCOAT code (Bohren and Huffman, 1983; Cheng et al., 2009) are utilized for homogeneous spherical particles and core-shell mixed spherical particles, respectively.

In the Mie theory (Mie, 1908), the scattering efficiency $\left(Q_{\mathrm{sp}}\right)$ and the hemispheric back scattering efficiency ( $\left.Q_{\mathrm{bsp}}\right)$ can be calculated by integrating the intensity function $|S(\theta, x, \tilde{m})|$ from $0^{\circ}$ to $180^{\circ}$ and from $90^{\circ}$ to $180^{\circ}$, respectively:

$Q_{\text {sp,bsp }}=\frac{1}{x^{2}} \int_{\theta}|S(\theta, x, \tilde{m})|^{2} \sin \theta d \theta$

where, $x=\pi D_{\mathrm{p}} / \lambda . D_{\mathrm{p}}$ is the volume equivalent diameter of particles. $\lambda$ is the wavelength of radiation. $\theta$ is the scattering angle. However, the integrating angle of TSI 3563 nephelometer is from $7^{\circ}$ to $170^{\circ}$ for scattering and from $90^{\circ}$ to $170^{\circ}$ for hemispheric backscattering, respectively. And the light source of the nephelometer is not strictly Lambertian and shows a non-ideal angular response (Anderson et al., 1996). These two effects are considered in the modified BHMIE code and BHCOAT code. The $\sin \theta$ term in Eq. (2) is replaced by angular sensitivity curves $f(\theta)_{\text {sp }}$ and $f(\theta)_{\text {bsp }}$, derived from a characterization study of TSI 3563 nephelometer (Anderson et al., 1996). Then the $\sigma_{\mathrm{sp}}$ and $\sigma_{\mathrm{bsp}}$ could be calculated following:

$$
\begin{aligned}
\sigma_{\mathrm{sp}, \mathrm{bsp}}= & \int_{D_{\mathrm{p}}}\left[\frac{1}{x^{2}} \int_{\theta}|S(\theta, x, \tilde{m})|^{2} f(\theta)_{\mathrm{sp}, \mathrm{bsp}} d \theta\right] \\
& \cdot\left(\frac{\pi}{4} D_{\mathrm{p}}^{2}\right) \cdot N\left(\log D_{\mathrm{p}}\right) \cdot d \log D_{\mathrm{p}}
\end{aligned}
$$

where $N\left(\log D_{\mathrm{p}}\right)$ is the PNSD.

\subsection{Retrieval algorithm}

As shown in Sect. 4.1, the HBF measured by the nephelometer is always between the values calculated with assumptions of external mixture and core-shell mixture of LAC. The calculated HBF is found to be sensitive to $r_{\text {ext-LAC. }}$. Therefore, based on the aerosol model described in Sect. 3.1, it is possible to retrieve $r_{\text {ext-LAC }}$ by matching the measured HBF and the HBF calculated from measured PNSD and LAC mass concentration with the modified Mie model.

The PNSD of externally mixed LAC particles and coreshell mixed particles, as well as the radii of the LAC core of core-shell mixed particles, are need to calculate the HBF. For a given $r_{\text {ext-LAC, }}$, the PNSD of externally mixed LAC particles can be calculated by

$N\left(\log D_{\mathrm{p}}\right)_{\mathrm{ext}-\mathrm{LAC}}=N\left(\log D_{\mathrm{p}}\right)_{\text {measure }} \cdot f_{\mathrm{LAC}} \cdot r_{\mathrm{ext}-\mathrm{LAC}}$

where, $N\left(\log D_{\mathrm{p}}\right)_{\text {measure }}$ is the PNSD measured by TDMPS and APS. $f_{\text {LAC }}$ is the volume fraction of LAC, which can be calculated by

$$
f_{\mathrm{LAC}}=\frac{M_{\mathrm{LAC}, \text { measure }}}{\rho_{\mathrm{LAC}} \cdot \sum_{D_{\mathrm{p}}} N\left(\log D_{\mathrm{p}}\right)_{\text {measure }} \cdot\left(\frac{\pi}{6} \cdot D_{\mathrm{p}}^{3}\right)}
$$


where, $M_{\mathrm{LAC}}$ measure is the LAC mass concentration measured by MAAP. $\rho_{\text {LAC }}$ is the density of LAC, which is reported in literature with a range from $1.00 \mathrm{~g} \mathrm{~cm}^{-3}$ to $2.00 \mathrm{~g} \mathrm{~cm}^{-3}$ (Sloane et al., 1983, 1984, 1991; Sloane and Wolff, 1985; Ouimette and Flagan, 1982; Seinfeld and Pandis, 1998). A median value of $1.5 \mathrm{~g} \mathrm{~cm}^{-3}$ is used in this study.

Accordingly, the PNSD of core-shell mixed particles can be calculated as:

$N\left(\log D_{\mathrm{p}}\right)_{\text {core-shell }}=N\left(\log D_{\mathrm{p}}\right)_{\text {measure }} \cdot\left(1-f_{\mathrm{LAC}} \cdot r_{\mathrm{ext}-\mathrm{LAC}}\right)(6)$

Another critical parameter for calculating the optical properties of core-shell mixed particles is the size of the LAC core. Core-shell mixed particles with the same diameter might differ in the size of their cores. As a simplified optical aerosol model, the core-shell mixed particles with the same diameter are assumed to be the same in the size of the LAC core, which can be calculated as:

$D_{\text {core }}=D_{\mathrm{p}} \cdot\left(\frac{f_{\mathrm{LAC}}-f_{\mathrm{LAC}} \cdot r_{\mathrm{ext}-\mathrm{LAC}}}{1-f_{\mathrm{LAC}} \cdot r_{\mathrm{ext}-\mathrm{LAC}}}\right)^{\frac{1}{3}}$

As shown in Eqs. (4), (6) and (7), the input parameters of the Mie model are the functions of $r_{\text {ext-LAC. Therefore, the HBF }}$ calculated with the Mie model is a function of $r_{\text {ext-LAC. The }}$ best estimation of $r_{\text {ext-LAC }}$ is the one which minimizes the differences between the calculated HBF and the corresponding measured value. The deviation $\chi^{2}$ is quantified by linear least squares in the form of:

$\chi^{2}=\sum_{i=1}^{3}\left(\frac{\mathrm{HBF}_{\text {calc }, i}-\mathrm{HBF}_{\text {measure }, i}}{\mathrm{HBF}_{\text {measure }, i}}\right)^{2}$

where $i$ denotes the three operation wavelengths of the TSI

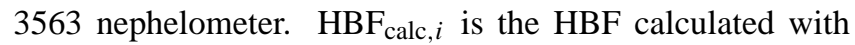
Mie model, while $\mathrm{HBF}_{\text {meausre, } i}$ is the $\mathrm{HBF}$ measured by nephelometer. The relationship between measured and calculated HBF at $700 \mathrm{~nm}$ is quite different from that at 450 and $550 \mathrm{~nm}$. The measured HBF at $700 \mathrm{~nm}$ is too high, so most of them are around the calculated values of core-shell mixture. Heintzenberg et al. (2006) performed a laboratory comparison study for 12 commercial nephelometers. Compared to calculated values, a systematic deviation of about $-20 \%$ was found for $\sigma_{\mathrm{sp}, 700 \mathrm{~nm}}$ of TSI 3563 nephelometer. Such large underestimation of $\sigma_{\mathrm{sp}, 700 \mathrm{~nm}}$ would lead to a significant overestimation of $\mathrm{HBF}$ at $700 \mathrm{~nm}$. Thus, only the $\mathrm{HBF}$ at 450 and $550 \mathrm{~nm}$ are used here to retrieve the $r_{\text {ext-LAC. }}$.

During the entire period of the HaChi summer campaign, 1-min-resolution data measured by nephelometer and MAAP were averaged to match the time of the 10-min-resolution PNSD records. The $r_{\text {ext-LAC }}$ was subsequently retrieved by minimizing the $\chi^{2}$ defined in Eq. (8).

It should be noted that the $r_{\text {ext-LAC }}$ defined in Sect. 3.1 is a parameter in a simplified aerosol optical model and would only be valid under some assumptions mentioned before.
The actual mixing state of aerosols in the atmosphere is far more complicated beyond the model capabilities. Thus, the retrieved $r_{\text {ext-LAC }}$ is an "effective parameter" and should not be used for quantitative analysis for the mixing state of LAC. However, the retrieved $r_{\text {ext-LAC }}$ can be considered as an indicator for the variation of LAC mixing state and used in aerosol optical calculations, which is of great value in the research of aerosol and the estimation of the direct radiative forcing.

\subsection{PartMC-MOSAIC model}

The PartMC-MOSAIC model (Riemer et al., 2009) was applied to simulate the diurnal variation of the mixing state of LAC. The PartMC-MOSAIC is a stochastic particle-resolved aerosol box model, capable of resolving the composition of an individual particle. A Monte Carlo approach is used in the PartMC model to simulate the coagulation process stochastically. Emissions and dilutions within the lower free tropospheric above the nocturnal boundary layer on a regional scale are also modeled in a stochastic manner. And a new aerosol chemistry model MOSAIC (Model for Simulating Aerosol interactions and Chemistry, Zaveri et al., 2008) is coupled in the PartMC to simulate the gas- and particlephase chemistry, particle phase thermodynamics, and dynamic gas-particle mass-transfer in a deterministic manner. The PartMC-MOSAIC model can predict number, mass and composition distributions of the aerosol population.

\section{Results and discussion}

\subsection{Calculated HBF based on the limiting mixing states of LAC: a closure study}

During the HaChi summer campaign, the PNSDs, LAC mass concentrations, scattering and hemispheric backscattering coefficients for dried aerosols were continuously measured on-line. An optical closure study on aerosol scattering and absorption coefficients has been conducted by Ma et al. (2011), which showed that the data are of high quality. The time series of aerosol volume concentrations, effective radii, LAC mass concentrations, as well as the LAC volume fractions for the whole period of the campaign are shown in Fig. 1a and b. It can be seen that all of these parameters vary greatly with time, mainly in response to synoptic weather systems. Diurnal cycles are also present during some periods. The average aerosol volume concentration for the diameter range from $3 \mathrm{~nm}$ to $10 \mu \mathrm{m}$ is $59.74 \mu \mathrm{m}^{3} \mathrm{~cm}^{-3}$, with a 5th percentage value of $15.92 \mu \mathrm{m}^{3} \mathrm{~cm}^{-3}$ and a 95 th percentage value of $137.49 \mu^{3} \mathrm{~cm}^{-3}$. The average aerosol effective radius, defined as $r_{\mathrm{eff}}=\int_{r_{\min }}^{r_{\max }} n(r) r^{3} d r / \int_{r_{\min }}^{r_{\max }} n(r) r^{2} d r$, is $185.15 \mathrm{~nm}$, with a 5 th percentage value of $151.14 \mathrm{~nm}$ and a 95th percentage value of $229.07 \mathrm{~nm}$. The average LAC mass concentration is $6.65 \mu \mathrm{g} \mathrm{m}^{-3}$, with a 5th percentage value of 


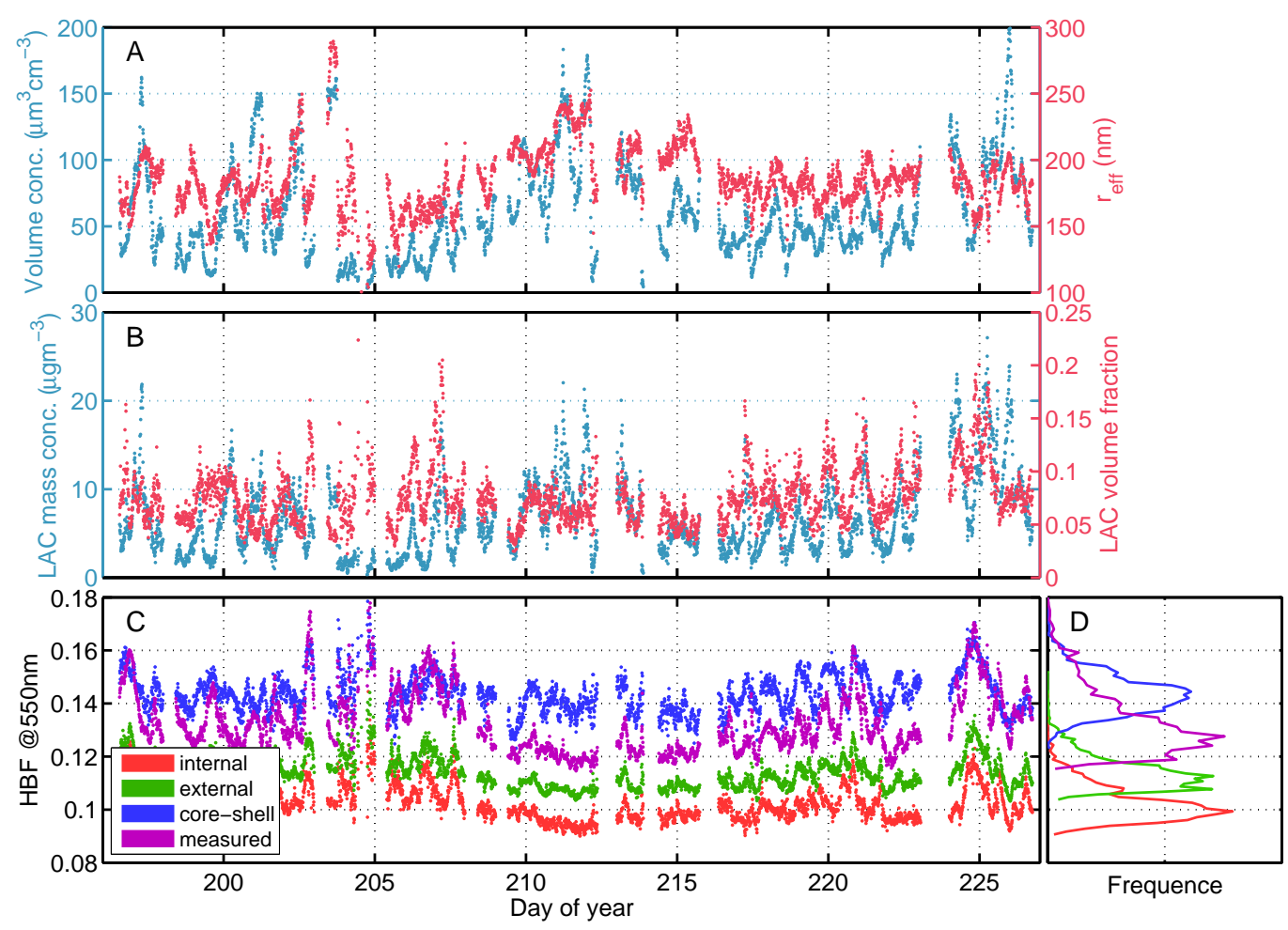

Fig. 1. Time series of selected parameters during the HaChi summer campaign: (A) aerosol volume concentration, effective radius, (B) LAC mass concentration, LAC volume fraction, (C) HBF measured by nephelometer and HBF calculated with three limiting mixing states of LAC at the wavelength of $550 \mathrm{~nm}$. (D) frequency distributions of measured and calculated HBF. All the data have been averaged corresponding to the time of TDMPS measurement with time resolution of $10 \mathrm{~min}$.

$1.59 \mu \mathrm{g} \mathrm{m}^{-3}$ and a 95th percentage value of $15.87 \mu \mathrm{g} \mathrm{m}^{-3}$. Futher details on aerosol optical properties for the HaChi summer campaign can be found in Ma et al. (2011).

To simulate the measurements of nephelometer, the HBF was calculated with the Mie model and the aerosol model introduced in Sect. 3 based on the measured PNSDs and LAC mass concentrations. The mixing state of LAC and less absorbing component was also needed in the simulation. Since there was no information on the mixing state of ambient aerosols available, the HBF was calculated for three limiting mixing states of LAC: external mixture, homogeneously internal mixture and core-shell mixture. Figure 1c shows the calculation results at the wavelength of $550 \mathrm{~nm}$, as well as the HBFs yielded from nephelometer measurements. Figure 1d presents the frequency of each time series of HBFs in Fig. 1c.

It can be seen that the three calculated HBFs vary with time, which is caused by the variations of PNSDs and LAC mass concentrations. The relative standard deviations of calculated HBFs at $550 \mathrm{~nm}$ are respectively $5.2 \%, 6.3 \%$ and $5.1 \%$ for the three assumptions of LAC mixing state mentioned above. However, it should be noted that the differences between the three time series of calculated HBF are more significant than the variations of each time series. The mean values of the three calculated HBF are shown in Ta- ble 1. For $550 \mathrm{~nm}$, the calculated HBF under the external mixture assumption $\left(\mathrm{HBF}_{\text {calc, external }}\right)$ is $11.4 \%$ higher than that under the homogeneously internal mixture assumption $\left(\mathrm{HBF}_{\text {calc, internal }}\right)$. The calculated HBF under the core-shell mixture assumption $\left(\mathrm{HBF}_{\text {calc,core-shell }}\right)$ is even $41.0 \%$ higher than that under the homogeneously internal mixture assumption. These differences are much higher than the variations of each time series caused by the variations of PNSDs and LAC mass concentrations. Therefore, the calculated HBF is more sensitive to the mixing state of LAC rather than the variations of PNSDs and LAC mass concentrations. This sensitivity of HBF provides an approach to retrieve the mixing state of LAC, as described in Sect. 3.

In Fig. 1c, the purple dots denote the HBF yielded from the nephelometer measurements $\left(\mathrm{HBF}_{\text {neph }}\right)$, i.e. the ratio of measured hemispheric backscattering coefficients to measured scattering coefficients. If the widely-used assumption that the atmospheric aerosol is a partial mixture of externally mixed and homogeneously internally mixed particles is appropriate, the $\mathrm{HBF}_{\text {neph }}$ values should fall between the $\mathrm{HBF}_{\text {calc, external }}$ and the $\mathrm{HBF}_{\text {calc, internal }}$. However, for $550 \mathrm{~nm}$, almost all of the $\mathrm{HBF}_{\text {neph }}$ are higher than the $\mathrm{HBF}_{\text {calc, external }}$ and $\mathrm{HBF}_{\text {calc, internal, and distributed be- }}$ tween the $\mathrm{HBF}_{\text {calc,external }}$ and the $\mathrm{HBF}_{\text {calc, core-shell. Table } 1}$ 
shows the averages of $\mathrm{HBF}_{\text {calc, external, }} \mathrm{HBF}_{\text {calc, internal, }}$ $\mathrm{HBF}_{\text {calc,core-shell }}$ and $\mathrm{HBF}_{\text {neph }}$ at the three operation wavelengths of the TSI 3563 nephelometer. It can be seen that the relationship of the calculated and measured $\mathrm{HBF}$ is $\mathrm{HBF}_{\text {calc, core-shell }}>\mathrm{HBF}_{\text {neph }}>\mathrm{HBF}_{\text {calc, external }}>\mathrm{HBF}_{\text {calc, internal }}$. The $\mathrm{HBF}_{\text {neph }}$ at $700 \mathrm{~nm}$ is higher than all of the calculated ones. This might be caused by the underestimation of the TSI 3563 nephelometer on $\sigma_{\mathrm{sp}, 700 \mathrm{~nm}}$, as mentioned in Sect. 3.3.

The mixing state of atmospheric aerosols is considered as an intermediate state between external and internal (Winkler, 1973). The internal mixture are usually treated as a homogeneously internal mixture in aerosol optical calculations (Wex et al., 2002b; Mallet et al., 2004; Cheng et al., 2006). In that case, external mixture and homogeneously internal mixture are two limiting cases of mixing state. The aerosol optical properties calculated with the assumptions of external mixture and homogeneously internal mixture should be the boundaries of the measured values. However, as presented in this study, the $\mathrm{HBF}_{\text {neph }}$ is significantly higher than both

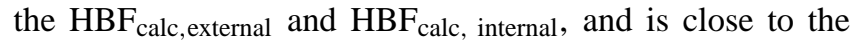

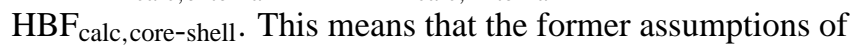
LAC mixing state, which have been widely used in aerosol optical calculations, are generally not appropriate. In the $\mathrm{NCP}$, the ambient aerosols seem to be more similar to coreshell mixtures, rather than to homogeneously internal mixtures. The aerosols can be considered as a partial mixture of externally and core-shell mixed particles.

\subsection{Retrieved mixing state of LAC}

The $r_{\text {ext-LAC }}$ was retrieved with the new method introduced in Sect. 3 for the whole period of the HaChi summer campaign. The time series of $r_{\text {ext-LAC }}$ is presented in Fig. $2 \mathrm{~b}$. The corresponding wind direction and wind speed measured by an automatic weather station are illustrated in Fig. 2a.

For the whole period, $r_{\text {ext-LAC }}$ varied between 0 and 1 , with an average of $0.51 \pm 0.21$, indicating that the mixing state of LAC is a combination of external and core-shell mixture. Pronounced variation can be found in the time series of $r_{\text {ext-LAC}}$, reflecting the large variation of LAC mixing state with time. Moreover, significant diurnal cycles of $r_{\text {ext-LAC }}$ can be discerned during some periods. The time-scale of the measured variability can be also revealed by autocorrelation analysis (Cheng et al., 2008). Figure $2 \mathrm{~d}$ depicts the result of the autocorrelation analysis for the entire time series of

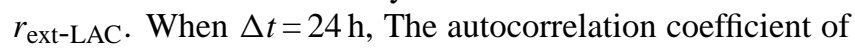

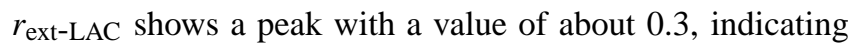
the existence of pronounced diurnal cycles in the variation of $r_{\text {ext-LAC. }}$

The average diurnal variation of $r_{\text {ext-LAC }}$ is illustrated in Fig. 2c, with error bar of one standard deviation. Consistent with the result of the autocorrelation analysis, a pronounced diurnal pattern can be found. Around midnight, the average $r_{\text {ext-LAC }}$ is around 0.58 and increases from 04:00 LT. A
Table 1. The average of calculated HBF under the assumptions of externally, homogeneously internally and core-shell mixture, as well as the averaged HBF measured by nephelometer.

\begin{tabular}{lrrrr}
\hline$\lambda(\mathrm{nm})$ & $\mathrm{HBF}_{\text {calc, external }}$ & $\mathrm{HBF}_{\text {calc, internal }}$ & $\mathrm{HBF}_{\text {calc, core-shell }}$ & $\mathrm{HBF}_{\text {neph }}$ \\
\hline 450 & 0.1099 & 0.0967 & 0.1424 & 0.1292 \\
550 & 0.1138 & 0.1023 & 0.1438 & 0.1329 \\
700 & 0.1251 & 0.1152 & 0.1498 & 0.1569 \\
\hline
\end{tabular}

maximum is reached at about 06:00 LT. And then $r_{\text {ext-LAC }}$ decreases rapidly after 08:00 LT with the minimum appearing in the afternoon. During the night, the average $r_{\text {ext-LAC }}$ increases again. This distinct diurnal pattern of average $r_{\text {ext-LAC }}$ reflects the diurnal variation of the mixing state of LAC and less absorbing component. During the night, the

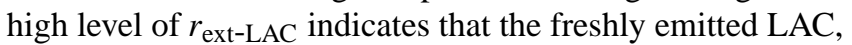
which is considered to be externally mixed with aged particles, accumulates in the nocturnal boundary layer. The low value of $r_{\text {ext-LAC }}$ during daytime reflects the dominance of core-shell mixed particles in the boundary layer. Similar diurnal pattern of aerosol mixing state was reported by Moffet and Prather (2009) and Liu et al. (2011).

\subsection{Diurnal variation of LAC mixing state: a case study}

To better understand the diurnal pattern of the $r_{\text {ext-LAC }}$ retrieved with this method, a period of 3 days (219-221 DOY) was selected for a case study. During this period, the synoptic conditions were relatively stable, dominated by easterly winds with speeds lower than $3 \mathrm{~ms}^{-1}$. The weather was cloud-free with no precipitation event occurred. Therefore, the aerosols in the boundary layer were mostly from local and regional emissions sources. With no obvious pollutant transport under this meteorological situation, this period was appropriate for investigating the diurnal variation of LAC mixing state caused by the evolution of boundary layer, emissions and corresponding chemical processes.

The time series of retrieved $r_{\text {ext-LAC }}$ during this period is presented in Fig. 3b. A similar diurnal pattern, with high $r_{\text {ext-LAC }}$ during night and low $r_{\text {ext-LAC }}$ during daytime, can be found in all of the three days.

During the whole period of the campaign, a high humidity tandem differential mobility analyser (HHTDMA, Hennig et al., 2005) was used to measure the hygroscopic growth factor (GF) at relative humidities of $90 \%, 95 \%$ and $98.5 \%$ for particles with dry diameters of $50 \mathrm{~nm}, 100 \mathrm{~nm}, 200 \mathrm{~nm}$ and $250 \mathrm{~nm}$, respectively. More details on the HHTDMA measurement can be found in Liu et al. (2011). The probability distributions of GF usually showed a distinct bimodal pattern, consisting of a dominant more-hygroscopic (MH) mode and a smaller nearly-hydrophobic (NH) mode. During the whole period, a strong diurnal pattern of the number fraction of these two modes was found, indicating the diurnal variation of the aerosol mixing state. For all of the four measured 
sizes, the number fraction of $\mathrm{NH}$ particles remains at a high level during the night and begins to decrease at 06:00 LT. During the daytime, the number fraction of $\mathrm{NH}$ stays at low level. And a rapid rise occurs around 18:00 LT. The high number fraction of $\mathrm{NH}$ particles during the night indicates that the freshly emitted hydrophobic particles have accumulated in the surface layer, apparently externally mixed with the hygroscopic particles. During the daytime, the low fraction of $\mathrm{NH}$ mode indicates that aged aerosol was dominant in the atmosphere near the surface (Liu et al., 2011). This result yielded from HHTDMA is well consistent with the diurnal variation of retrieved $r_{\text {ext-LAC. }}$.

In Liu's (2011) work, a stochastic, particle-resolved aerosol model PartMC-MOSAIC was applied to simulate the aerosol hygroscopicity for the same period as in this study. A good agreement between the model results and the measurements indicates that the model can be well representative of the hygroscopicity of ambient aerosols. To investigate how the chemical and meteorological processes affect the diurnal variation of the mixing state of LAC, the same model was applied in this study. The simulated scenario represented a Lagrangian air parcel over a large megacity region. The model was initialized $12 \mathrm{~h}$ before the simulation period for model adjustment. The mixing layer height was set according to the boundary layer height simulated by the Weather Research and Forecasting (WRF) model. The temperature and water vapour mixing ratio were set based on the measurement. The initial gas phase concentrations and emission rates were set according to Riemer et al. (2009). Based on the PNSDs measured by TDMPS and APS, a tri-modal distribution was used as the initial PNSD. The initial aerosols were assumed to consist of $\left(\mathrm{NH}_{4}\right)_{2} \mathrm{SO}_{4}$, primary organic aerosol and LAC, with mass fractions of $60 \%, 35 \%$ and $5 \%$, respectively. The aerosol emission pattern and chemical composition was set according to Riemer et al. (2009), while some modification was made to better represent the pollution in the North China Plain. More details about the parameter settings of the model can be found in Liu et al. (2011).

The model results are shown in Fig. 3c. The mass of the modelled externally mixed LAC is compared to the total mass of the modelled LAC to yield the $r_{\text {ext-LAC,model }}$. It can be seen that the simulated $r_{\text {ext-LAC,model }}$ for all the size ranges match well with the retrieved $r_{\text {ext-LAC }}$, indicating that the variation of the modelled result is well consistent with

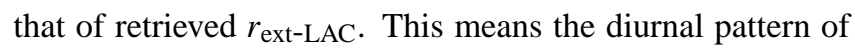
retrieved $r_{\text {ext-LAC }}$ can be explained by the mechanisms included in the model, such as emissions, aging processes and the entrainment by the increase of the mixing layer height. During the night, the freshly emitted LAC aerosols accumulate in the shallow nocturnal boundary layer and the aging processes are relatively weak. Under such a condition, the fraction of the externally mixed LAC to the total LAC mass is relatively high. As illustrated in Fig. 3c, more than $80 \%$ of LAC mass is externally mixed for the particles smaller than $125 \mathrm{~nm}$. In the morning during 07:00 LT to 12:00 LT, the development of the mixing layer causes a downward entrainment of aged aerosol from aloft, resulting in a decrease of the fraction of externally mixed LAC. The aging processes may also make contributions. Only less than $40 \%$ of LAC is externally mixed at noon. The fraction of externally mixed LAC remains low until the evening. The collapse of the mixing layer and the high emission rate due to rush hours cause a rapid increase in the fraction of externally mixed LAC, and the fraction remains high in the stable shallow nocturnal boundary layer. A sensitivity study of the modelled aerosol mixing state to the chemical and meteorological processes was performed by Liu et al. (2011). The results suggested that the diurnal evolution of the mixing layer was decisive in explaining the diurnal cycle of aerosol mixing state. Other processes such as condensation, photochemical aging and coagulation processes also made contributions but were not as effective as the evolution of the mixing layer. A similar boundary layer mechanism was also suggested by Rissler et al. (2006).

In Fig. 3c, the $r_{\text {ext-LAC,model }}$ for large particles are much lower than that for small ones. In the model, the initial aerosol for all size range is assumed to consist of LAC as $5 \%$ in mass, and the freshly emitted LAC particles are assumed to be distributed as a log-normal distribution with geometric average diameter of $50 \mathrm{~nm}$. Therefore, during the daytime as well as during the nighttime, the fraction of externally mixed LAC decreases with increasing particle size.

\subsection{Sensitivity study}

The input parameters of the new method include in situ measured data (PNSDs, LAC mass concentrations, aerosol scattering and hemispheric backscattering coefficients) and some constants assumed beforehand (the refractive indices of LAC and less absorbing component, the density of LAC and the mass absorption efficiency (MAE)). The retrieved $r_{\text {ext-LAC }}$ would no doubt be influenced by the uncertainties of these variables. Also, some assumptions included in the model, such as spherical particles and constant fraction of LAC mass for all size, would introduce uncertainties to the retrieved

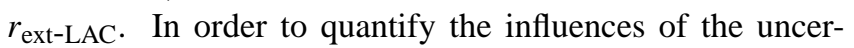
tainties of these input parameters and assumptions on the retrieved $r_{\text {ext-LAC }}$, a sensitivity study was performed. The potential uncertainties introduced by the assumptions in the model are discussed first. The sensitivity of the $r_{\text {ext-LAC }}$ to the input parameters was determined by varying them individually and evaluating the changing of the retrieved

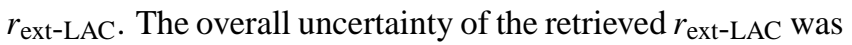
estimated by a Monte Carlo approach. 

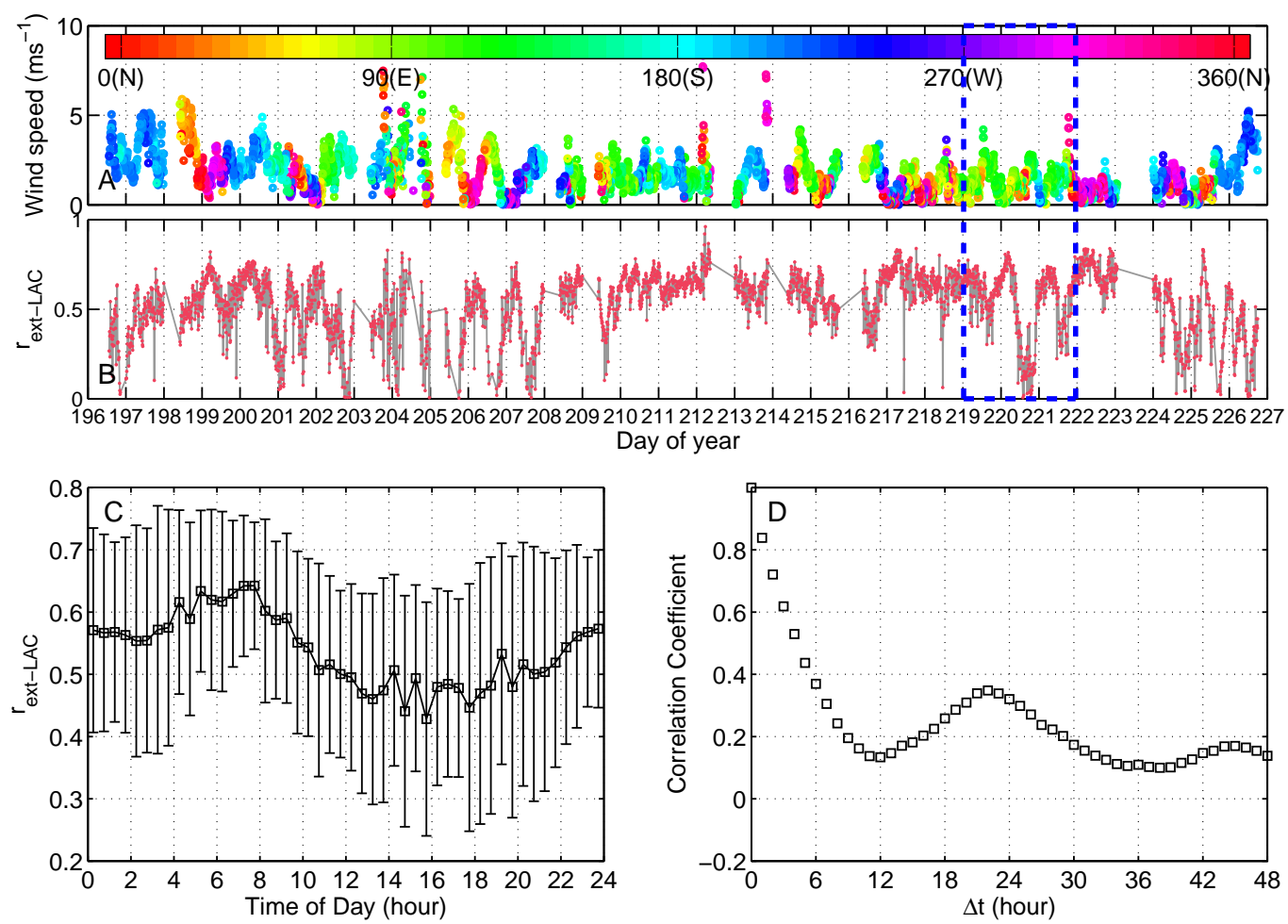

Fig. 2. (A) Time series of wind speed and wind direction (denoted by the colour of dots). (B) Time series of retrieved $r_{\text {ext-LAC }}$ (C) Average

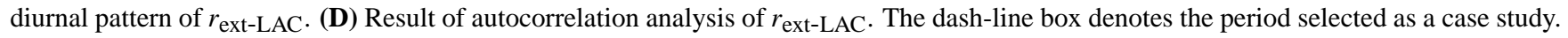

\subsubsection{Potential uncertainties introduced by the assumptions in the model}

The most important assumption in the Mie theory is that all particles are spherical. This assumption simplifies the mathematical treatment. However, atmospheric aerosols are sometimes non-spherical. Soot aggregates and mineral dust particles are typical and often observed as non-spherical aerosols (Katrinak et al., 1993; Okada et al., 2001; Kaaden et al., 2009). The shape of the particles may influence their optical properties. If the responses of the $\sigma_{\mathrm{sp}}$ and $\sigma_{\mathrm{bsp}}$ to the particle shape are different, a large uncertainty will be introduced in the retrieved $r_{\text {ext-LAC. }}$. Unfortunately, no literature mentioning the dependence of $\sigma_{\mathrm{bsp}}$ on particle shape was found. Therefore, it is difficult to quantify the influence of non-spherical particles on the retrieved $r_{\text {ext-LAC }}$.

However, there is some indirect evidence from which we may estimate the influence. Figure 4 shows the cumulative contributions of aerosols with different size to the optical properties (i.e. $\sigma_{\mathrm{sp}}, \sigma_{\mathrm{bsp}}$ and $\sigma_{\mathrm{ap}}$ ), which were derived with the Mie model, average PNSD and LAC mass concentration, and three assumed mixing states. It can be seen that at the wavelengths of 450 and $550 \mathrm{~nm}$, the scattering and hemispheric backscattering are dominated by the particles with the size range from 100 to $600 \mathrm{~nm}$ in diameter, which are also the main part of the accumulation mode (Hussein et al.,
2005). Freshly generated soot exists in the form of chainlike aggregates. However, during aging processing, a marked change in morphology of soot particles occurs. It was found that a transformation of the soot aggregates to spherical particles occurs as sulphuric acid and water condense onto fresh soot. Also, the soot core was restructured to more compact form (Zhang et al., 2008; Pagels et al., 2009). Therefore, the optical properties are thus considered to be mainly dominated by spherical particles.

For larger sizes, mineral dust particles with non-spherical shape exist. However, due to the huge concentrations of the fine particles in the NCP, the relative optical contribution is less than $20 \%$ for particles larger than $600 \mathrm{~nm}$, and is only about $5 \%$ for super-micron particles. There was no strong dust event observed during the $\mathrm{HaChi}$ summer campaign. The influence of the non-spherical mineral dust particles is thus ignored. It should be noted that LAC is usually observed to be non-spherical and in the form of aggregate structures (Katrinak et al., 1993). However, there is not enough information available to evaluate the influence of these agglomerates on the retrieved $r_{\text {ext-LAC. }}$

In the algorithm, only two kinds of particle morphology are assumed: externally mixed LAC and a LAC core surrounded by a less absorbing shell. In the atmosphere, externally mixed less absorbing particles should also exist. There have been few research results in the literature that provide 


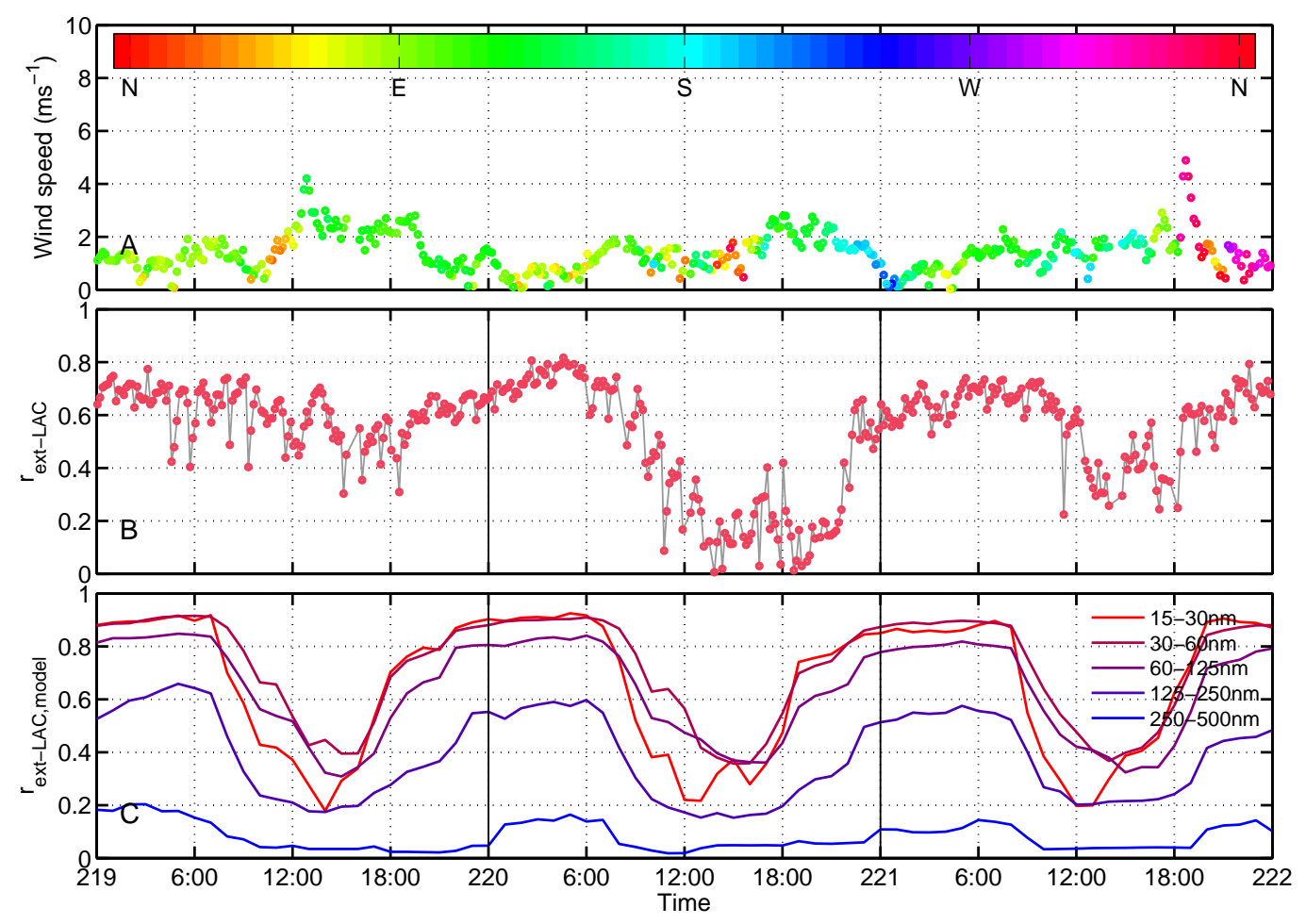

Fig. 3. Time series of parameters for the selected period: (A) wind speed and wind direction (denoted by the colour of dots), (B) the retrieved $r_{\text {ext-LAC }},(\mathbf{C})$ the fraction of externally mixed LAC at different size ranges yielded from the PartMC-MOSAIC model.

Table 2. $r_{\text {ext-LAC }}$ retrieved from assumed LAC volume fractions and measured LAC volume fractions.

\begin{tabular}{lrrr}
\hline case & $\begin{array}{r}\text { Inputs } \\
\text { (period for average) }\end{array}$ & $\begin{array}{r}r_{\text {ext-LAC (assumed }} \\
\text { LAC volume } \\
\text { fractions) }\end{array}$ & $\begin{array}{r}r_{\text {ext-LAC (measured }} \\
\text { LAC volume } \\
\text { fractions) }\end{array}$ \\
\hline average & Whole period & 0.587 & 0.555 \\
high $r_{\text {ext-LAC }}$ & DOY 220-220.25 & 0.744 & 0.724 \\
low $r_{\text {ext-LAC }}$ & DOY 220.5-220.75 & 0.183 & 0.102 \\
\hline
\end{tabular}

information on the fractions of particles under different mixing states. In a field campaign near Beijing, Wehner et al. (2009) used a volatility tandem DMA to determine the aerosol volatility based on the changes in particle diameter between $25^{\circ} \mathrm{C}$ and $300^{\circ} \mathrm{C}$. They found that most of the particles had a low to moderate volatile fraction, corresponding to the externally mixed LAC and core-shell mixed LAC. Around $40 \%$ of the particles with diameters smaller than $300 \mathrm{~nm}$ were found to have a large volatile fraction with over $55 \%$ decrease in diameter after heating. If the non-volatile core in the high volatile particles is very small, it might not consist of LAC but of low-volatile organic material (Kalberer et al., 2004), since freshly emitted LAC particles are usually at least $50 \mathrm{~nm}$ in diameter (e.g., Harris and Maricq, 2001). Therefore, there are some externally mixed less absorbing particles included in the high volatile group, with a number fraction lower than $40 \%$. To estimate the influence on the $r_{\text {ext-LAC }}$, the $r_{\text {ext-LAC }}$ was retrieved with the assumption that the externally mixed less absorbing particles exist with assumed number fractions. It was found that the retrieved

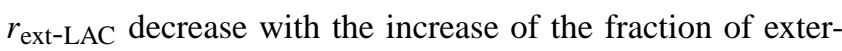
nally mixed less absorbing particles. The $r_{\text {ext-LAC }}$ is about $6 \%$ lower than the original value (with no less absorbing component externally mixed) if $20 \%$ of the less absorbing component is externally mixed. And the decrease in percentage goes up to $25 \%$ if $40 \%$ of the less absorbing component is externally mixed. 

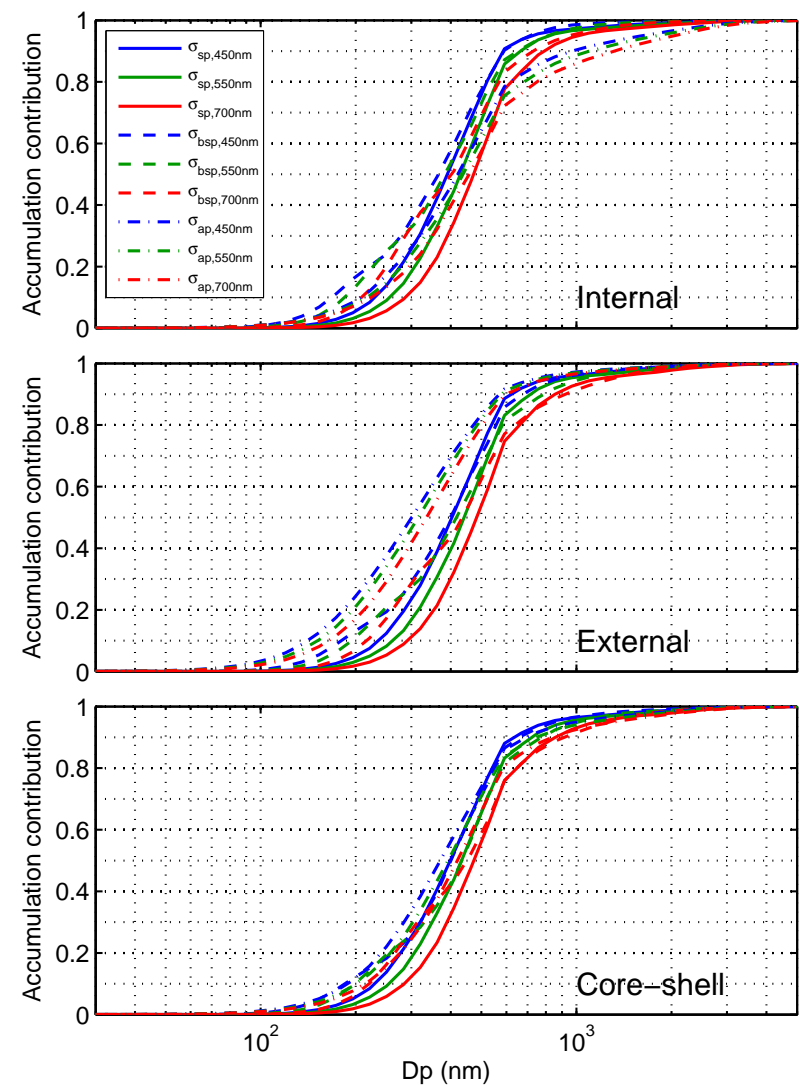

Fig. 4. The cumulative contributions of aerosols with different size to the optical properties: $\sigma_{\mathrm{sp}}, \sigma_{\mathrm{bsp}}$ and $\sigma_{\mathrm{ap}}$. The results is based on the Mie model, average PNSD and LAC mass concentration, and three assumed mixing states.

Another assumption included in the retrieving model is that the volume fraction of LAC is independent of particle size. This is no doubt the simplest description for LAC volume size distribution. The real situation in the atmosphere is much more complicated. Freshly emitted LAC particles are usually concentrated at around $100 \mathrm{~nm}$ in diameter (Moffet and Prather, 2009). During coagulations and condensation processes, the LAC mass will be transferred to larger particles. In order to evaluate the influence of this assumption on the retrieved $r_{\text {ext-LAC, }}$, the average EC volume fractions obtained from the Berner impactor measurements were used, which are shown in Fig. 5. The size-dependent volume fractions of LAC were assumed to be the same as that of EC. The $r_{\text {ext-LAC }}$ was retrieved from the size-independent LAC volume fractions and the average measured size-dependent LAC volume fractions, respectively. The calculations were carried out for three cases: average condition (using the average values for the whole period as the inputs of the model), high $r_{\text {ext-LAC }}$ case (using the average values for the period from DOY 220 to DOY 220.25 as the inputs), and low $r_{\text {ext-LAC }}$ case (using the average values for the period from DOY
Table 3. Uncertainties of the input parameters for the retrieving algorithm, giving in terms of one standard deviation.

\begin{tabular}{lr}
\hline Parameter & $\begin{array}{r}\text { Standard } \\
\text { deviation } \\
(\sigma, \%)\end{array}$ \\
\hline$D_{\mathrm{p}, \mathrm{TDMPS}}$ & 1.1 \\
$D_{\mathrm{p}, \mathrm{APS}}$ & 3 \\
$N_{\mathrm{TDMPS}, 3-20 \mathrm{~nm}}$ & 10 \\
$N_{\mathrm{TDMPS}, 20-200 \mathrm{~nm}}$ & 3.3 \\
$N_{\mathrm{TDMPS}, 200-700 \mathrm{~nm}}$ & 8.3 \\
$N_{\mathrm{APS}}$ & 3.3 \\
$\mathrm{HBF}_{\text {neph }}$ & 6.6 \\
$\sigma_{\mathrm{ap}}$ & 4 \\
$\mathrm{MAE}=6.6 \mathrm{~m}^{2} \mathrm{~g}^{-1}$ & 9.1 \\
$\rho_{\mathrm{LAC}}=1.5 \mathrm{~g} \mathrm{~cm}^{-3}$ & 11 \\
$n_{\text {non }}=1.55$ & 0.5 \\
$i_{\text {non }}=1 \mathrm{e}-7$ & 0 \\
$n_{\mathrm{LAC}}=1.80$ & 4 \\
$i_{\mathrm{LAC}}=0.54$ & 6.6 \\
\hline
\end{tabular}

220.5 to DOY 220.75 as the inputs). The results are presented in Table 2.

The values retrieved with the measured size-dependent fractions are always higher than those retrieved with the sizeindependent fractions. The sensitivity of retrieved $r_{\text {ext-LAC }}$ to the assumption of LAC volume fraction distribution is also found to be insignificant. For the average case, the difference between the two retrieved $r_{\text {ext-LAC }}$ is 0.032 . The difference for the high $r_{\text {ext-LAC }}$ case is only 0.02 . But for the low $r_{\text {ext-LAC }}$ case, the difference reaches up to 0.081 , which is relatively high. It seems that the lower the $r_{\text {ext-LAC }}$ is, the more sensitive it becomes.

The assumption of the size-independent LAC volume fraction distribution used in the model does cause an overestimation in the retrieved $r_{\text {ext-LAC }}$, but the influence is relatively small. The reason for choosing a size-independent LAC volume fraction is to make the method be able to provide information on the LAC mixing state solely from aerosol physical properties. Mobility size spectrometers have been widely used for measuring the PNSD. Nephelometers and MAAPs are also commonly used to provide aerosol optical properties. All of these instruments can measure the aerosol properties online with high time resolutions. However, the volume fraction distribution of LAC is usually obtained from aerosol chemical composition measurements, which is normally based on impactor sampling and offline analyzing. This kind of measurement is usually with low time resolution and not as common as the measurements of aerosol physical properties. Therefore, a method based on the aerosol physical property measurements is more valuable than that based on aerosol chemical data. 


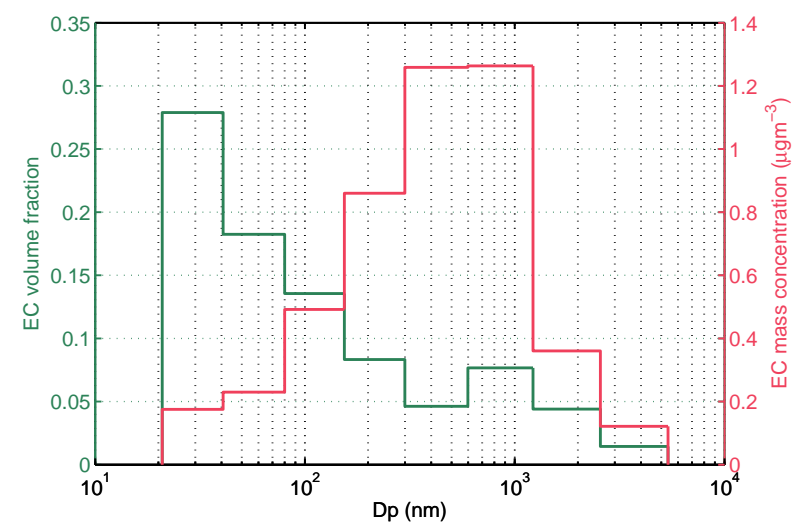

Fig. 5. The average distribution of EC mass concentration and EC volume fraction yielded from Berner impactor measurements.

\subsubsection{Uncertainties of input parameters}

All of the input parameters for the retrieving algorithm are listed in Table 3. The possible values of each parameter are assumed to be normally distributed with standard deviations presented in Table 3.

The uncertainty of the measured PNSD originates from the uncertainties of the TDMPS and APS measurements. From a comparison test reported by Wiedensohler et al. (2011), the maximum uncertainty of the particle size measured by mobility size spectrometers reaches $3.5 \%$, and the maximum uncertainty of the number concentration is $30 \%, 10 \%$ and $25 \%$ for the size range of $3-20 \mathrm{~nm}, 20-200 \mathrm{~nm}$ and 200 $700 \mathrm{~nm}$, respectively. These values are used as the uncertainties of the TDMPS measurement. For the size and number concentration measured by APS, the uncertainty is respectively estimated as $9 \%$ and $10 \%$ (Wex et al., 2002b). The uncertainty of $\sigma_{\text {ap }}$ measured by MAAP is reported as about $12 \%$ (Petzold et al., 2004). To convert $\sigma_{\text {ap }}$ to LAC mass concentration, a MAE of $6.6 \mathrm{~m}^{2} \mathrm{~g}^{-1}$ is used in the MAAP. In order to estimate the uncertainty of this value, the Berner impactor-derived EC mass concentrations were compared with the MAAP-measured $\sigma_{\text {ap }}$, as shown in Fig. 6. It should be noted that LAC and EC are two different definitions and have slightly different thermal, optical and chemical behaviour. However, they share a similar fraction of the carbonaceous aerosol and are supposed to be comparable (Lavanchy et al., 1999). Thus, the LAC mass concentration is assumed to be the same as the Berner impactor-derived EC mass concentration. It can be seen that all data points locate around the line of MAE $=6.6 \mathrm{~m}^{2} \mathrm{~g}^{-1}$, with determination coefficient $R^{2}$ of 0.837 . The coefficient of linear regression is $7.20 \mathrm{~m}^{2} \mathrm{~g}^{-1}$, which is close to the MAE value used in MAAP. Since there is no direct way to evaluate the uncertainty of MAE, the difference between the recommended value and the value yielded from the regression is taken as one standard deviation of the MAE, which is $9.1 \%$. This
Table 4. $r_{\text {ext-LAC }}$ retrieved with each input parameter varying from its original value to the original value plus $\sigma$, as well as the differences $(\Delta)$ between each new $r_{\text {ext-LAC }}$ and original value.

\begin{tabular}{lrrr}
\hline Parameters & average & high $r_{\text {ext-LAC }}$ & low $r_{\text {ext-LAC }}$ \\
\hline original & $0.587(0)$ & $0.744(0)$ & $0.183(0)$ \\
$D_{\text {TDMPS }}$ & $0.566(-0.021)$ & $0.731(-0.013)$ & $0.136(-0.047)$ \\
$N_{\text {TDMPS }}$ & $0.545(-0.042)$ & $0.716(-0.028)$ & $0.097(-0.086)$ \\
$D_{\text {APS }}$ & $0.600(+0.013)$ & $0.750(+0.006)$ & $0.195(+0.012)$ \\
$N_{\text {APS }}$ & $0.586(-0.001)$ & $0.743(-0.001)$ & $0.180(-0.003)$ \\
$\mathrm{HBF}_{\text {neph }, 450 \mathrm{~nm}}$ & $0.464(-0.123)$ & $0.667(-0.077)$ & $0(-0.183)$ \\
$\mathrm{HBF}_{\text {neph }, 550 \mathrm{~nm}}$ & $0.479(-0.108)$ & $0.670(-0.074)$ & $0(-0.183)$ \\
$\sigma_{\text {ap }}$ & $0.604(+0.017)$ & $0.755(+0.011)$ & $0.216(+0.033)$ \\
MAE & $0.548(-0.039)$ & $0.719(-0.025)$ & $0.105(-0.078)$ \\
LAC density & $0.540(-0.047)$ & $0.713(-0.031)$ & $0.089(-0.094)$ \\
$n_{\text {non }}$ & $0.612(+0.025)$ & $0.760(+0.016)$ & $0.219(+0.036)$ \\
$n_{\text {LAC }}$ & $0.611(+0.024)$ & $0.760(+0.016)$ & $0.240(+0.057)$ \\
$i_{\text {LAC }}$ & $0.610(+0.023)$ & $0.759(+0.015)$ & $0.229(+0.046)$ \\
\hline
\end{tabular}

value is an empirical estimation and only valid in this study. The corresponding uncertainty of the MAE $(3 \sigma)$ is also illustrated in Fig. 6 as dash lines. In literature (Sloane et al., 1983, 1984, 1991; Sloane and Wolff, 1985; Ouimette and Flagan, 1982; Seinfeld and Pandis, 1998), $\rho_{\mathrm{EC}}$ is reported as a range from $1.00 \mathrm{~g} \mathrm{~cm}^{-3}$ to $2.00 \mathrm{~g} \mathrm{~cm}^{-3}$. Accordingly, the uncertainty of $\rho_{\mathrm{EC}}$ is set to be $33 \%$ to cover the above mentioned range. The uncertainties for the refractive indices of LAC and less absorbing component are chosen according to Cheng et al. (2006). Their estimated uncertainties for the real part of refractive index of the less absorbing component, the real part and imaginary part of refractive index of LAC are $1.5 \%, 12 \%$ and $20 \%$, respectively. The uncertainty of the HBF derived from the nephelometer measurements is estimated as $20 \%$ (Anderson et al., 1996).

\subsubsection{Sensitivities of retrieved $r_{\text {ext-LAC }}$ to the uncertainties of input parameters}

The sensitivities of the retrieved $r_{\text {ext-LAC }}$ to the uncertainty of each input parameter were investigated for three cases: average condition (using the average values for the whole period as the inputs of the model), high $r_{\text {ext-LAC }}$ case (using the average values for the period from DOY 220 to DOY 220.25 as the inputs), and low $r_{\text {ext-LAC }}$ case (using the average values for the period from DOY 220.5 to DOY 220.75 as the inputs). The $r_{\text {ext-LAC }}$ was retrieved with one parameter varying from its original value to the original plus one $\sigma$, while keeping other parameters fixed. The difference between the new $r_{\text {ext-LAC }}$ and the original value, defined as $\Delta=r_{\text {ext-LAC, new }}{ }^{-}$ $r_{\text {ext-LAC, original, }}$, represents the influence of the uncertainty of the varying input parameter on $r_{\text {ext-LAC. }}$. In other words, the influences of the uncertainties of input parameters on the retrieved $r_{\text {ext-LAC }}$ were determined independently. Table 4 presents the $r_{\text {ext-LAC }}$ retrieved with the varying of each parameter, as well as the difference $(\Delta)$. It can be noted from 


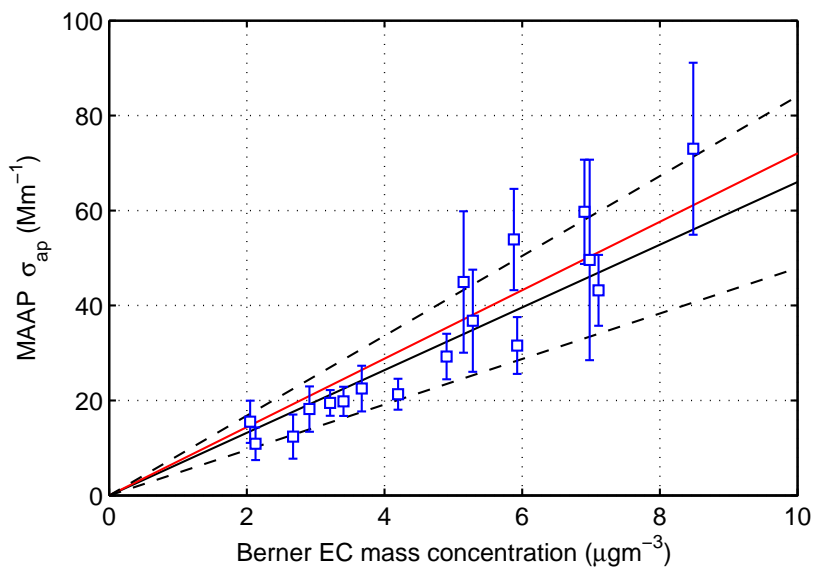

Fig. 6. Comparison of the $\sigma_{\text {ap }}$ measured by MAAP and the Berner impactor-derived EC mass concentrations. The result of linear regression is shown as red line $\left(\mathrm{b}=7.20 \mathrm{~m}^{2} \mathrm{~g}^{-1}, R^{2}=0.837\right)$. The black line corresponds with $\mathrm{MAE}=6.6 \mathrm{~m}^{2} \mathrm{~g}^{-1}$. The error bar of each data point denotes the standard deviation of the $\sigma_{\text {ap }}$ averaged to yield the data, since the time resolution of $\sigma_{\mathrm{ap}}$ is much higher than that of the impactor-derived EC mass concentrations.

Table 3 that, among all of the input parameters, the largest

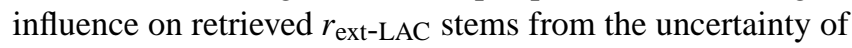
HBF. A shift of $6.6 \%$ in HBF leads to a shift of more than 0.1 in $r_{\text {ext-LAC }}$ for the average case. However, it should be noted that there is no reference in the literature to the uncertainties of $\sigma_{\text {bsp }}$ or HBF measured by the TSI 3563 nephelometer. Only one reference (Anderson et al., 1996) mentioned that the uncertainty of HBF derived by the TSI 3563 nephelometer is within $20 \%$. Therefore, the influence of the uncertainty of measured HBF should be reconsidered after getting a better estimation of the uncertainty of the measurement.

The second largest influence on retrieved $r_{\text {ext-LAC comes }}$ from the uncertainty of LAC density. Due to the large range of LAC density reported in the literature, the standard deviation of LAC density is estimated as $11 \%$, which is the highest among all of the input parameters. This high standard deviation of LAC density induces a shift of 0.047 in $r_{\text {ext-LAC }}$ for the average case.

Following the LAC density, the uncertainty of measured LAC mass concentration also makes a great contribution. The uncertainty of LAC mass concentration is separated into two parts, the uncertainty of the measured $\sigma_{\text {ap }}$ and the uncertainty of the MAE, and treated separately. For the average case, a shift of $4 \%$ in measured $\sigma_{\text {ap }}$ leads to a shift of 0.017 in $r_{\text {ext-LAC }}$, while a shift of $9.1 \%$ in MAE leads to a shift of 0.039 in $r_{\text {ext-LAC }}$ for the average case.

The influences of the uncertainties in the refractive indices on $r_{\text {ext-LAC }}$ are of the same magnitude. A shift of one $\sigma$ in each of the three assumed refractive indices respectively causes a shift of around 0.024 in $r_{\text {ext-LAC }}$ for the average case.
For the PNSD, a shift of one $\sigma$ in the size and number concentration of TDMPS measurement leads to a shift of 0.021 and 0.042 in $r_{\text {ext-LAC }}$ for the average case, respectively. However, it can be seen that the influence of the uncertainties in the APS data on $r_{\text {ext-LAC }}$ is weak. Since an averaged PNSD was used in this sensitivity study, the contribution of particles in the size range of the APS measurements to the overall aerosol optical properties is relatively small. During certain heavy pollution periods, the contribution of coarse particles to the overall aerosol optical properties might be significant. In those cases, the influence of the uncertainties in the APS

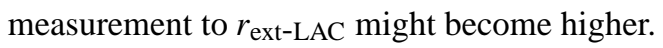

It should be noted that the influences of the uncertainties of model inputs on $r_{\text {ext-LAC }}$ also depend on the levels of $r_{\text {ext-LAC }}$. The lower the $r_{\text {ext-LAC }}$ is, the more significant the influence would be. It means that the $r_{\text {ext-LAC }}$ with low values have more uncertainty than those with high values. This also can be seen in Fig. 3b, $r_{\text {ext-LAC }}$ with lower values show much larger variability than those with higher values.

Overall, the retrieved $r_{\text {ext-LAC }}$ shows the highest sensitivity to the HBF yielded from the nephelometer measurements, followed by the assumed LAC density. The uncertainty in the LAC mass concentration also makes great contribution. The uncertainties in the refractive indices of less absorbing component and LAC cause similar responses in $r_{\text {ext-LAC. And the }}$ influence of the uncertainties in measured PNSD on $r_{\text {ext-LAC }}$ is relatively low among the input parameters. Therefore, under current method, an accurate measurement of $\sigma_{\mathrm{sp}}$ and $\sigma_{\mathrm{bsp}}$ is most important to retrieve $r_{\text {ext-LAC. }}$ A better estimation of the uncertainties in measured $\sigma_{\mathrm{bsp}}$ or $\mathrm{HBF}$ is urgently needed. Furthermore, more accurate estimations of the LAC density and the refractive indices are required to reduce the uncertainty of retrieved $r_{\text {ext-LAC. }}$.

\subsubsection{Monte Carlo variations}

A Monte Carlo simulation was applied to investigate the overall influence of input parameters on the retrieved $r_{\text {ext-LAC }}$ for the three cases mentioned in Sect. 4.4.3. The retrieving algorithm was repeated using a randomly varying set of input parameters. The random values of the input parameters were generated independently. The values of each input parameter were normally distributed, with the original value used in Sect. 4.4.3 as the mean value, and the standard deviation listed in Table 3. 2000 runs were carried out to yield a stable distribution of the retrieved $r_{\text {ext-LAC. The retrieved }}$ $r_{\text {ext-LAC }}$ shows a quasi-lognormal distribution with standard deviations of $0.202,0.130$ and 0.241 for the average case, high $r_{\text {ext-LAC }}$ case, and low $r_{\text {ext-LAC }}$ case, respectively. Such large uncertainty in the retrieved $r_{\text {ext-LAC }}$ is induced by all input parameters. However, all the uncertainties of input parameters discussed in Sect. 4.4.2 are the worst case estimations, thus the standard deviation of $r_{\text {ext-LAC }}$ might be lower. 


\section{Summary and conclusions}

In this paper, a new method was proposed to retrieve information on the mixing state of LAC from measured PNSDs, LAC mass concentrations and HBFs.

Based on a two-parameter optical aerosol model, an aerosol optical closure was conducted using independent in situ measured data. The HBFs yielded from the nephelometer were compared with the values calculated from the PNSDs and LAC mass concentrations with a modified Mie model. Three limiting mixing states of LAC were assumed in the calculation: external mixture, homogeneously internal mixture and core-shell mixture. It was found that the HBF is more sensitive to the assumption of LAC mixing state, rather than to the variations of the PNSDs or the LAC mass concentrations. The HBFs calculated based on core-shell mixture are much higher than those based on external mixture or homogeneously internal mixture. Moreover, almost all of the HBFs yielded from the nephelometer locate between the values calculated based on core-shell mixture and external mixture, but are much higher than the values calculated under the homogeneously internal mixture assumption. This finding indicates that the assumption of LAC mixing state which has been widely applied in aerosol optical calculations cannot be used properly in the NCP. In this area, the internally mixed aerosols are rather core-shell mixed than homogeneously mixed. Thus, an assumption of a system consisting of externally mixed LAC and core-shell mixed LAC and less absorbing component is more appropriate in aerosol optical calculations.

With the new method, a high-resolution time series of the mass fraction of the externally mixed LAC was retrieved from in situ measurements of PNSDs and LAC mass concentrations. A pronounced diurnal cycle was found. During the night, the average $r_{\text {ext-LAC }}$ is around 0.58 , and reaches its maximum around 06:00 LT, indicating the accumulation of the freshly emitted LAC in the nocturnal boundary layer. During the daytime, $r_{\text {ext-LAC }}$ remains at a relatively low level, reflecting the dominance of aged aerosol in the boundary layer. This diurnal variation of $r_{\text {ext-LAC }}$ is mainly caused by the diurnal evolution of the mixing layer. Other processes, such as condensation, coagulation and photochemical aging, also make contributions. As a case study, a three-day period with constant synoptic situation was selected. A stochastic, particle-resolved aerosol model PartMC-MOSAIC was applied to yield the information of LAC mixing state during this period. The retrieved $r_{\text {ext-LAC }}$ and the model results showed a very similar variation patterns. This good agreement further proves our explanations for the diurnal pattern of the retrieved $r_{\text {ext-LAC. }}$.

A sensitivity study was carried out to investigate the sensitivities of the retrieved $r_{\text {ext-LAC }}$ to the input parameters of the algorithm. The retrieved $r_{\text {ext-LAC }}$ shows the highest sensitivity to the HBF yielded from the nephelometer measurements, followed by the assumption of the LAC density. The uncertainties in the LAC mass concentrations and the refractive indices also cause great influences on $r_{\text {ext-LAC. It was }}$ found that $r_{\text {ext-LAC }}$ with low values have more uncertainty than those with high values. The overall uncertainty of the retrieved $r_{\text {ext-LAC }}$ was derived via the Monte Carlo approach. Considering the uncertainties of all input parameters of the algorithm, the standard deviation of the retrieved $r_{\text {ext-LAC }}$ was found to be 0.20 for average case.

Acknowledgements. This work is supported by the National Natural Science Foundation of China (NSFC) under Grant No. 40875001 and by the German Science Foundation under grant DFG WI 1449/14-1. Funds for this experiment were also provided by: China 973 project 2011CB403402, NSFC project 40975083 and Basic Research Fund of China Academy of Meteorological Sciences 2008Z011.

Edited by: D. Covert

\section{References}

Anderson, T. L. and Ogren, J. A.: Determining aerosol radiative properties using the TSI 3563 Integrating Nephelometer, Aerosol Sci. Technol., 29, 57-69, 1998.

Anderson, T. L., Covert, D. S., Marshall, S. F., Laucks, M. L., Charlson, R. J., Waggoner, A. P., Ogren, J. A., Caldow, R., Holm, R. L., Quant, G., Sem, J., Wiedensohler, A., Ahlquist, N. A., and Bates, T. S.: Performance characteristics of a High-sensitivity, three-wavelength total scatter/backscatter nephelometer, J. Atmos. Ocean. Tech., 13, 967-986, 1996.

Albrecht, B. A.: Aerosols, cloud microphysics, and fractional cloudiness, Science, 245, 1227-1230, 1989.

Bohren, C. F. and Huffman, D. R.: Absorption and Scattering of Light by Small Particles, John Wiley, Wiley, New York, USA, 1983.

Bond, T. C. and Bergstrom, R. W.: Light absorbing by carbonaceous particles: An investigative review, Aerosol Sci. Tech., 40, 27-67, 2006.

Bond, T. C. and Sun, H. L.: Can reducing black carbon emission counteract global warming?, Environ. Sci. Technol., 39, 59215926, 2005.

Bond, T. C., Streets, D. G., Yarber, K. F., Nelson, S. M., Woo, J.H., and Klimont, Z:: A technology-based global inventory of black and organic carbon emissions from combustion, J. Geophys. Res., 109, D14203, doi:10.1029/2003jd003697, 2004.

Chandra, S., Satheesh, S. K., and Srinivasan, J.: Can the state of mixing of black carbon aerosols explain the mystery of "excess" atmospheric absorption?, Geophys. Res. Lett., 31, L19109, doi:10.1029/2004GL020662, 2004.

Charlson, R. J., Schwartz, S. E., Hales, J. M., Cess, R. D., Coakley Jr., J. A., Hansen, J. E., and Hofmann, D. J.: Climate forcing by anthropogenic aerosols, Science, 255, 423-430, doi:10.1126/science.255.5043.423, 1992.

Cheng, Y. F., Eichler, H., Wiedensohler, A., Heintzenberg, J., Zhang, Y. H., Hu, M., Herrmann, H., Zeng, L. M., Liu, S., Gnauk, T., Brüggemann, E., and He, L. Y.: Mixing state of elemental carbon and less absorbing aerosol components 
derived from in situ particle optical properties at Xinken in Pearl River Delta of China, J. Geophys. Res., 111, D20204, doi:10.1029/2005JD006929, 2006.

Cheng, Y. F., Wiedensohler, A., Eichler, H., Su, H., Gnauk, T., Brüggemann, E., Herrmann, H., Heintzenberg, J., Slanina, J., Tuch, T., Hu, M., and Zhang, Y. H.: Aerosol optical properties and related chemical apportionment at Xinken in Pearl River Delta of China, Atmos. Environ., 42, 6351-6372, 2008.

Cheng, Y. F., Berghof, M., Garland, R. M., Wiedensohler, A., Wehner, B., Müller, T., Su, H., Zhang, Y. H., Achtert, P., Nowak, A., Pöschl, U., Zhu, T., Hu, M., and Zeng, L. M.: Influence of soot mixing state on aerosol light absorption and single scattering albedo during air mass aging at a polluted regional site in northeastern China, J. Geophys. Res., 114, D00G10, doi:10.1029/2008JD010883, 2009.

Clarke, A. D., Shinozuka, Y., Kapustin, V. N., Howell, S., Huebert, B., Doherty, S., Anderson, T., Covert, D., Anderson, J., Hua, X., Moore II, K. G., McNaughton, C., Carmichael, G., and Weber, R.: Size distributions and mixtures of dust and black carbon aerosol in Asian outflow: Physiochemistry and optical properties, J. Geophys. Res, 109, D15S09, doi:10.1029/2003JD004378, 2004.

Cooke, W. F., Liousse, C., Cachier, H., and Feichter, J.: Construction of a $1 \times 1$ fossil fuel emission data set for carbonaceous aerosol and implementation and radiative impact in the ECHAM4 model, J. Geophys. Res., 104, 22137-22162, 1999.

Covert, D. S., Heintzenberg, J., and Hansson, H. C.: Electro-optical detection of external mixtures in aerosols, Aerosol Sci. Technol., 12, 446-456, 1990.

d'Almeida, G. A., Koepke, P., and Shettle, E. P.: Atmospheric Aerosols-Global Climatology and Radiative Characteristics, A. Deepak, Hampton, Va, 1991.

Dey, S., Tripathi, S. N., and Mishra, S. K.: Probable mixing state of aerosols in the Indo-Gangetic Basin, northern India, Geophys. Res. Lett., 35, L03808, doi:10.1029/2007GL032622, 2008.

Harris, J. S. and Maricq, M. M.: Signature size distributions for diesel and gasoline engine exhaust particulate matter, J. Aerosol Sci., 32, 749-764, 2001.

Hasan, H. and Dzubay, T. G.: Apportioning light extinction coefficients to chemical species in atmospheric aerosol, Atmos. Environ., 17, 1573-1581, 1983.

Heintzenberg, J., Wiedensohler, A., Tuch, T. M., Covert, D. S., Sheridan, P., Ogren, J. A., Gras, J., Nessler, R., Kleefeld, C., Kalivitis, N., Aaltonen, V., Wilhelm, R. T., and Havlicek, M.: Intercomparsions and aerosol calibrations of 12 commercial integrating nephelometer of 15 three manufacturers, J. Atmos. Ocean. Tech., 23, 902-914, 2006.

Hennig, T., Massling, A., Brechtel, F. J., and Wiedensohler, A.: A tandem DMA for highly temperature-stabilized hygroscopic particle growth measurements between $90 \%$ and $98 \%$ relative humidity, J. Aerosol Sci., 36, 1210-1223, doi:10.1016/j.jaerosci.2005.01.005, 2005.

Hussein, T., Dal Maso, M., Petaja, T., Koponen, I. K., Paatero, P., Aalto, P. P., Hameri, K., and Kulmala, M.: Evaluation of an automatic algorithm for fitting the particle number size distributions, Boreal Environ. Res., 10, 337-355, 2005.

IPCC: Climate Change 2007 - The Physical Science Basis, edited by: Solomon, S., Cambridge University Press, New York, USA, 2007.
Jacobson, M. Z.: A physically-based treatment of elemental carbon optics: Implications of 25 global direct forcing of aerosols, Geophys. Res. Lett., 27, 217-220, 2000.

Jacobson, M. Z.: Strong radiative heating due to the mixing state of black carbon in atmospheric aerosols, Nature, 409, 695-697, 2001.

Kaaden, N., Massling, A., Schladitz, A., Müller, T., Kandler, K., Schütz, L., Weinzierl, B., Petzold, A., Tesche, M., Leinert, S., Deutscher, C., Ebert, M., Weinbruch, S., Wiedensohler, A.: State of mixing, shape factor, number size distribution, and hygroscopic growth of the Saharan anthropogenic and mineral dust aerosol at Tinfou, Morocco, Tellus, 61B, 51-63, 2009.

Kalberer, M., Paulsen, D., Sax, M., Steinbacher, M., Dommen, J., Prevot, A. S. H., Fisseha, R., Weingartner, E., Frankevich, V., Zenobi, R., Baltensperger, U.: Identification of polymers as major components of atmospheric organic aerosols, Science, 303, 1659-1662, 2004.

Katrinak, K. A., Rez, P., and Buseck, P. R.: Structural variations in individual carbonaceous particles from an urban aerosol, Environ. Sci. Technol., 26, 1967-1976, 1992.

Katrinak, K. A., Rez, P., Perkes, P. R., and Buseck, P. R.: Fractal geometry of carbonaceous aggregates from an urban aerosol, Environ. Sci. Technol, 27, 539-547, 1993.

Khalizov, A. F., Xue, H., Wang, L., Zheng, J., and Zhang, R.: Enhanced light absorption and scattering by carbon soot aerosol internally mixed with sulfuric acid, J. Phys. Chem. A, 113, 10661074, doi:10.1021/jp807531n, 2009.

Kristjansson, J. E.: Studies of the aerosol indirect effect from sulfate and black carbon aerosols, J. Geophys. Res., 107, 4246, doi:10.1029/2001JD000887, 2002.

Lavanchy, V. M. H., Gäggeler, H. W., Nyeki, S., and Baltensperger, U.: Elemental carbon (EC) and black carbon (BC) measurements with a thermal method and an aethalometer at the high-alpine research station Jungfraujoch, Atmos. Environ., 33, 2759-2769, 1999.

Liu, P., Zhao, C., Zhang, Q., Deng, Z., Huang, M., Ma, X., and Tie, X.: Aircraft study of aerosol vertical distributions over Beijing and their optical properties, Tellus B, 61, 756-767, 2009.

Liu, P. F., Zhao, C. S., Göbel, T., Hallbauer, E., Nowak, A., Ran, L., Xu, W. Y., Deng, Z. Z., Ma, N., Mildenberger, K., Henning, S., Stratmann, F., and Wiedensohler, A.: Hygroscopic properties of aerosol particles at high relative humidity and their diurnal variations in the North China Plain, Atmos. Chem. Phys., 11, 3479-3494, doi:10.5194/acp-11-3479-2011 2011.

Ma, N., Zhao, C. S., Nowak, A., Müller, T., Pfeifer, S., Cheng, Y. F., Deng, Z. Z., Liu, P. F., Xu, W. Y., Ran, L., Yan, P., Göbel, T., Hallbauer, E., Mildenberger, K., Henning, S., Yu, J., Cheng, L. L., Zhou, X. J., Stratmann, F., and Wiedensohler, A.: Aerosol optical properties in the North China Plain during HaChi campaign: an in-situ optical closure study, Atmos. Chem. Phys. Discuss., 11, 9567-9605, doi:10.5194/acpd-11-9567-2011, 2011.

Mallet, M., Roger, J. C., Despiau, S., Putaud, J. P., and Dubovik. O.: A study of the mixing state of black carbon in urban zone, $\mathrm{J}$ Geophys. Res., 109, D04202, doi:10.1029/2003JD003940, 2004.

Mie, G.: Beiträge zur optic trüber Medien speziell kolloidaler Metallösungen, Ann. Phys., 25, 377-445, 1908.

Moffet, R. C. and Prather, K. A.: In-situ measurements of the mixing state and optical properties of soot with implications for radiative forcing estimates, Proc. Natl. Acad. Sci., 106, 11872 
11877, doi:10.1073/pnas.0900040106, 2009.

Moffet, R. C., Qin, X. Y., Rebotier, T., Furutani, H., and Prather, K. A.: Chemically segregated optical and microphysical properties of ambient aerosols measured in a singleparticle mass spectrometer, J. Geophys. Res., 113, D12213, doi:10.1029/2007JD009393, 2008.

Myhre, G., Stordal, F., Restad, K., and Isaksen, I.: Estimates of the direct radiative forcing due to sulphate and soot aerosols, Tellus, Ser. B, 50, 463-477, 1998.

Okada, K., Heintzenberg, J., Kai, K., and Qin, Y.: Shape of atmospheric mineral particles collected in three Chinese arid-regions, J. Geophys. Res., 28, 3123-3126, 2001.

Ouimette, J. R. and Flagan, R. C.: The extinction coefficient of multicomponent aerosols, Atmos. Environ., 16, 2405-2419, 1982.

Pagels, J., Khalizov, A. F., McMurry, P. H., and Zhang, R.: Processing of soot by controlled sulphuric acid and water condensationmass and mobility relationship, Aerosol Sci. Technol., 43, 629640, 2009.

Petzold, A. and Schönlinner, M.: Multi-angle absorption photometry - a new method for the measurement of aerosol light absorption and atmospheric black carbon, J. Aerosol Sci., 35, 421-441, 2004.

Petzold, A., Kramer, H., and Schönlinner, M.: Continuous Measurement of Atmospheric Black Carbon Using a Multi-Angle Absorption Photometer, Environ. Sci. Poll. Res., 4, 78-82, 2002.

Ramanathan, V. and Carmichael, G.: Global and regional climate changes due to black carbon, Nature Geosci., 1, 221-227, doi:10.1038/ngeo156, 2008.

Ran, L., Zhao, C., Geng, F., Tie, X., Tang, X., Peng, L., Zhou, G., Yu, Q., Xu, J., and Guenther, A.: Ozone photochemical production in urban Shanghai, China: Analysis based on ground level observations, J. Geophys. Res., 114, D15301, doi:10.1029/2008JD010752, 2009.

Riemer, N., West, M., Zaveri, R. A., and Easter, R. C.: Simulating the evolution of soot mixing state with a particleresolved aerosol model, J. Geophys. Res., 114, D09202, doi:10.1029/2008jd011073, 2009.

Rissler, J., Vestin, A., Swietlicki, E., Fisch, G., Zhou, J., Artaxo, P., and Andreae, M. O.: Size distribution and hygroscopic properties of aerosol particles from dry-season biomass burning in Amazonia, Atmos. Chem. Phys., 6, 471-491, doi:10.5194/acp6-471-2006, 2006.

Rosenfeld, D.: TRMM observed first direct evidence of smoke from forest fires inhibiting rainfall, Geophys. Res. Lett., 26, 31053180, 1999.

Rosenfeld, D.: Suppression of rain and snow by urban and industrial air pollution, Science, 287, 1793-1796, 2000.

Schwarz, J. P., Spackman, J. R., Fahey, D. W., Gao, R. S., Lohmann, U., Stier, P., Watts, L. A., Thomson, D. S., Lack, D. A., Pfister, L., Mahoney, M. J., Baumgardner, D., Wilson, J. C., and Reeves, J. M.: Coatings and their enhancement of black carbon light absorption in the tropical atmosphere, J. Geophys. Res., 113, D03203, doi:10.1029/2007JD009042, 2008.

Seinfeld, J. and Pandis, S.: Atmospheric chemistry and physics: from air pollution to climate change, Wiley, Inc., New York, USA, 1998.

Sloane, C. S.: Optical properties of aerosols - Comparison of measurements with model calculations, Atmos. Environ., 17, 409416, 1983.
Sloane, C. S.: Optical properties of aerosols of mixed composition, Atmos. Environ., 18, 871-878, 1984.

Sloane, C. S. and Wolff, G. T.: Prediction of ambient light scattering using a physical model responsive to relative humidity: Validation with measurements from Detroit, Atmos. Environ., 30 19, 669-680, 1985.

Sloane, C. S., Watson, J., Chow, J., Pritchett, L., and Richards, L.W.: Size-segregated fine particle measurements by chemical species and their impact on visibility impairment in Denver, Atmos. Environ., Part A, 25, 1013-1024, 1991.

Street, D. G., Gupta, S., Waldhoff, S. T., Wang, M. Q., Bond, T. C., and Bo, Y.: Black carbon emission in China, Atmos. Environ., 35, 4281-4296, 2001.

Tang, I. N. and Munkelwitz, H. R.: Water activities, densities and refractive indices of aqueous sulfates and sodium nitrate droplets of atmospheric importance, J. Geophys. Res., 99, 18801-18808, 1994.

Tuch, T. M., Haudek, A., Müller, T., Nowak, A., Wex, H., and Wiedensohler, A.: Design and performance of an automatic regenerating adsorption aerosol dryer for continuous operation at monitoring sites, Atmos. Meas. Tech., 2, 417-422, doi:10.5194/amt-2-417-2009, 2009.

Twomey, S.: Pollution and the planetary albedo, Atmos. Environ., 8, 1251-1256, 1974.

van Donkelaar, A., Martin, R. V., Brauer, M., Kahn, R., Levy, R., Verduzco, C., and Villeneuve, P. J.: Global estimates of ambient fine particulate matter concentrations from satellite-based aerosol optical depth: Development and application, Environ. Health Persp., 118, 847-855, 2010.

Wehner, B., Berghof, M., Cheng, Y. F., Achtert, P., Birmili, W., Nowak, A., Wiedensohler, A., Garland, R. M., Pöschl, U., $\mathrm{Hu}$, M., and Zhu, T.: Mixing state of non-volatile aerosol particle fractions and comparison with light absorption in the polluted Beijing region, J. Geophys. Res., 114, D00G17, doi:10.1029/2008JD010923, 2009.

Wex, H.: Closure and sensitivity studies on physical parameters of rural continental aerosols, Ph.D. Thesis, Leipzig University, 2002a.

Wex, H., Neusüß, C., Wendisch, M., Stratmann, F., Koziar, C., Keil, A., Wiedensohler, A., and Ebert, M.: Particle scattering, backscattering, and absorption coefficients: An in situ closure and sensitivity study, J. Geophys. Res., 107, 8122, doi:10.1029/2000JD000234, 2002b.

Wiedensohler, A., Birmili, W., Nowak, A., Sonntag, A., Weinhold, K., Merkel, M., Wehner, B., Tuch, T., Pfeifer, S., Fiebig, M., Fjäraa, A. M., Asmi, E., Sellegri, K., Depuy, R., Venzac, H., Villani, P., Laj, P., Aalto, P., Ogren, J. A., Swietlicki, E., Roldin, P., Williams, P., Quincey, P., Hglin, C., Fierz-Schmidhauser, R., Gysel, M., Weingartner, E., Riccobono, F., Santos, S., Grning, C., Faloon, K., Beddows, D., Harrison, R. M., Monahan, C., Jennings, S. G., O’Dowd, C. D., Marinoni, A., Horn, H.-G., Keck, L., Jiang, J., Scheckman, J., McMurry, P. H., Deng, Z., Zhao, C. S., Moerman, M., Henzing, B., and de Leeuw, G.: Particle mobility size spectrometers: harmonization of technical standards and data structure to facilitate high quality long-term observations of atmospheric particle number size distributions, Atmos. Meas. Tech. Discuss., 3, 5521-5587, doi:10.5194/amtd-3-55212010, 2010.

Winkler, P.: The growth of atmospheric aerosol particles as a 
function of the relative humidity - II An improved concept of mixed nuclei, J. Aerosol Sci., 4, 373-387, 1973.

Xu, W. Y., Zhao, C. S., Ran, L., Deng, Z. Z., Liu, P. F., Ma, N., Lin, W. L., Xu, X. B., Yan, P., He, X., Yu, J., Liang, W. D., and Chen, L. L.: Characteristics of pollutants and their correlation to meteorological conditions at a suburban site in the North China Plain, Atmos. Chem. Phys., 11, 4353-4369, doi:10.5194/acp-114353-2011, 2011.
Zaveri, R. A., Easter, R. C., Fast, J. D., and Peters, L. K.: Model for simulating aerosol interactions and chemistry (MOSAIC), J. Geophys. Res., 113, D13204, doi:10.1029/2007jd008782, 2008.

Zhang, R., Khalizov, A. F., Pagels, J., Zhang, D., Xue, H., McMurry, P. H.: Variability in morphology, hygroscopicity, and optical properties of soot aerosols during atmospheric processing, P. Natl. Acad. Sci. USA, 105, 10291-10296, 2008.

Zhao, C. S., Tie, X. X., and Lin, Y. P.: A possible positive feedback of reduction of precipitation and increase in aerosols over eastern central China, Geophys. Res. Lett., 33, L11814, doi:10.1029/2006GL025959, 2006. 